\title{
Impaired iron recycling from erythrocytes is an early iron-dependent hallmark of aging
}

Pratik Kumar Mandal ${ }^{1 *}$, Patryk Slusarczyk ${ }^{1 *}$, Gabriela Zurawska ${ }^{1}$, Magdalena Cybulska ${ }^{2}$, Olga Krawczyk $^{2}$, Michal Mikula², Sylwia Herman ${ }^{3}$, Malgorzata Lenartowicz ${ }^{3}$, Remigiusz Serwa ${ }^{4}$, Wojciech Pokrzywa $^{1}$ and Katarzyna Mleczko-Sanecka ${ }^{1 \#}$

${ }^{1}$ International Institute of Molecular and Cell Biology in Warsaw, Poland

${ }^{2}$ Maria Sklodowska-Curie National Research Institute of Oncology, Warsaw, Poland

${ }^{3}$ Department of Genetics and Evolution, Institute of Zoology and Biomedical Research, Jagiellonian University, Cracow, Poland

${ }^{4}$ The International Institute of Molecular Mechanisms and Machines Polish Academy of Sciences, Warsaw, Poland

* equal contribution

\# To whom correspondence may be addressed:

Katarzyna Mleczko-Sanecka, International Institute of Molecular and Cell Biology, 4 Ks. Trojdena Street, 02-109 Warsaw, Poland Tel.: (+48 22) 5970700.

Fax: (+48 22) 59707 15. E-mail: kmsanecka@iimcb.gov.pl 


\begin{abstract}
Aging affects iron homeostasis and erythropoiesis, as evidenced by tissue iron loading in rodents and common anemia in the elderly. Since red pulp macrophages (RPMs) continuously process iron, their cellular functions might be susceptible to age-dependent decline, affecting organismal iron metabolism and red blood cells (RBCs) parameters. However, little is known about the effects of aging on the functioning of RPMs. To study aging RPMs, we employed 10-11-months-old female mice that show serum iron deficiency and iron overload primarily in spleens compared to young controls. We observed that this is associated with iron loading, oxidative stress, diminished mitochondrial and lysosomal activities, and most relevantly, decreased erythrophagocytosis rate in RPMs. We uncovered that these impairments of RPMs lead to the retention of senescent RBCs in the spleen, their excessive local hemolysis, and the formation of iron- and heme-rich large extracellular protein aggregates, likely derived from damaged RBCs and RPMs. We further found that feeding mice an iron-reduced diet alleviates iron accumulation and reactive oxygen species build-up in RPMs, restores mitochondrial and lysosomal functions, and improves their ability to clear erythrocytes. Consequently, this diet improves splenic RBCs fitness, limits hemolysis and formation of iron-rich aggregates, normalizes splenic iron levels, and tends to increase serum iron availability in aging mice. Mechanistically, using readouts from aged RPMs and in vitro cultures of RPM-like cells, we show that diminished erythrophagocytic activity of RPMs can be attributed to a combination of increased iron levels, reduced expression of hemecatabolizing enzyme heme oxygenase 1 (HO-1), and endoplasmic reticulum stress. Taken together, we identified RPM dysfunction as an early hallmark of physiological aging and demonstrated that dietary iron reduction improves iron turnover efficacy.
\end{abstract}

\title{
Introduction
}

Sufficient iron supplies are critical for metabolic cellular functions and red blood cells (RBCs) production (Cronin et al., 2019; Muckenthaler et al., 2017). As a key constituent of heme - a prosthetic group of hemoglobin, iron confers the unique capability of RBCs to shuffle oxygen and carbon dioxide between the lungs and tissues (Slusarczyk and Mleczko-Sanecka, 2021). At the systemic level, 80\% of circulating iron is utilized for hemoglobin synthesis during the daily generation of approximately 200 billion RBCs (Muckenthaler et al., 2017). Hence, in mammals, hemoglobin accounts for the largest pool of heme and iron in the body (Hamza and Dailey, 2012). The oxygen-carrying capacity of RBCs renders them sensitive to the progressive build-up of reactive oxygen species (ROS) that drive natural RBCs senescence (Bratosin et al., 1998). Due to the prooxidative properties of free heme and iron, the exceedingly high hemoglobin content in physiologically senescent RBCs constitutes a threat to other cells in the event of RBC breakdown. To reduce the risk of RBCs disintegrating in the blood vessels and because mammals evolved under limited dietary iron availability, $90 \%$ of the body iron needs are met by internal iron recycling from aged RBCs (Ganz, 2012). This task is accomplished by macrophages, 
predominantly red pulp macrophages (RPMs) of the spleen, cells that recognize and engulf defective RBCs in the process called erythrophagocytosis (EP) (Bian et al., 2016; Youssef et al., 2018).

The loss of elasticity is a key feature of naturally aged RBCs (Bratosin et al., 1998; Higgins, 2015; Lutz, 2012). One of the underlying mechanisms is oxidation and denaturation of hemoglobin, as well as the formation of lipid peroxides (Arashiki et al., 2013; Ganz, 2012). Once RBCs become too rigid to pass through slits within the red pulp's unique venous system, they are retained within the spleen cords (Mebius and Kraal, 2005). Recognition of 'trapped' RBCs by RPMs involves additional signals proposed to act in an additive fashion (Gottlieb et al., 2012; Slusarczyk and Mleczko-Sanecka, 2021). Upon engulfment by RPMs, RBCs are degraded in phagolysosomes, globins are hydrolyzed to amino acids, and heme is released (Klei et al., 2017). Recent findings suggest that in addition to phagocytosis, part of the RBC-derived iron is recovered via hemolysis of RBCs within the splenic microenvironment and subsequent endocytic hemoglobin uptake (Klei et al., 2020). In RPMs, heme is transported from phagolysosomes or late endosomes to the cytoplasm by HRG1 (Pek et al., 2019) and subsequently catabolized by heme oxygenase 1 (HO-1; encoded by Hmox-1) to carbon monoxide (CO), biliverdin, and ferrous iron that feeds labile iron pool (LIP) (Kovtunovych et al., 2010). Lack of HO-1 in mice leads to a progressive loss of RPMs due to heme-driven toxicity and fibrosis in the red pulp of the spleen (Kovtunovych et al., 2010). The nanocage-like protein ferritin sequesters iron from the LIP. Iron efflux from RPMs occurs via ferroportin (FPN) to replenish the transferrin-bound iron pool in the plasma (Muckenthaler et al., 2017; Zhang et al., 2011). The process of iron release from RPMs is tightly regulated by hepcidin, a small liver-derived hormone that mediates FPN degradation and/or occlusion, hence preventing iron release from the RPMs iron reservoir (Aschemeyer et al., 2018; Nemeth et al., 2004). Despite the growing body of knowledge, it is still unclear how the iron balance in RPMs is regulated in pathophysiological conditions and how it may affect their functions.

Similar to erythropoiesis, the rate of RBCs sequestration is very high, reaching 2-3 million per second in humans (Higgins, 2015), and mainly considered constitutive under physiological conditions. Some reports observed an increased rate of EP in response to inflammation (Bennett et al., 2019; Bian et al., 2016). Recent work employing genetic mouse models showed altered calcium signaling in RPMs due to overactivation of the PIEZO1 mechanoreceptor (Ma et al., 2021) or deficiency of the IL-33 receptor IL1RL1 (Lu et al., 2020), induces or represses EP rate, respectively. However, it is largely unknown if the RBCs uptake and lysis rates are regulated by intrinsic or systemic iron status per se.

Iron dyshomeostasis hallmarks physiological aging. This is exemplified by progressive iron accumulation and iron-dependent oxidative damage in aging organs, such as the brain, liver, spleen, kidney, skeletal muscles, or heart (Arruda et al., 2013; Cook and Yu, 1998; Sukumaran et al., 2017; Xu et al., 2008). At the same time, plasma iron deficiency is frequent in aged individuals and is a leading cause of a condition referred to as anemia in the elderly (Girelli et al., 2018). RPMs are derived from embryonic progenitor cells (Yona et al., 2013), exhibit limited self-renewal capacity (Hashimoto et al., 2013), and are only partially replenished by blood monocytes during aging (Liu et al., 2019). Hence, 
bioRxiv preprint doi: https://doi.org/10.1101/2022.01.16.476518; this version posted January 19, 2022. The copyright holder for this preprint (which was not certified by peer review) is the author/funder, who has granted bioRxiv a license to display the preprint in perpetuity. It is made available under aCC-BY-ND 4.0 International license.

these specialized cells continuously perform senescent RBCs clearance during their lifespan, thus processing and providing most of the iron utilized by the organism. We hypothesized that this might render RPMs particularly susceptible to age-related iron-triggered functional deterioration, affecting body iron indices and RBCs homeostasis. Here, we identify the diminished EP capacity of RPMs in older mice and propose that this functional impairment affects local RBCs' balance in the spleen, promotes their lysis, and the formations of iron- and heme-containing extracellular protein aggregates. We decipher new mechanisms of EP regulation by an interplay between intracellular iron levels, HO-1 activity, and proteotoxic endoplasmic reticulum (ER) stress. Finally, we provide evidence that reducing dietary iron during aging 'rejuvenates' RPMs function and improves iron homeostasis.

\section{Results}

\section{RPMs of aged mice show increased labile iron levels and diminished erythrophagocytic activity}

To investigate iron recycling capacity during aging, we used 10-11-month-old mice fed a diet with standard iron content (200 ppm). We used female mice, as they show a higher iron burden in the spleen with the age progression (Altamura et al., 2014). This age in mice corresponds to approximately 40-45 years in humans when senescent changes begin to occur (Fox, 2006). As expected, aged mice show tissue iron loading, with the spleen being most affected, followed by the liver and other organs such as muscles and the heart (Fig. 1A and B, Fig. S1 A and B). Aging mice exhibit decreased blood hemoglobin values, as previously shown (Peters et al., 2008), and a drop in transferrin saturation, a feature that thus far was observed mostly in elderly humans (Fig. 1C and D) (Girelli et al., 2018). Next, we aimed to verify if aging specifically affects the iron status and essential cellular functions of RPMs. Ferritin is an iron-storing heteropolymer composed of $\mathrm{H}$ and $\mathrm{L}$ subunits. Due to its ferroxidase activity, $\mathrm{H}$ ferritin is a key endogenous protective protein that converts redox-active ferrous iron to inert ferric iron retained inside the ferritin shells (Mleczko-Sanecka and Silvestri, 2021). Using intracellular staining and flow cytometric analyses, we uncovered that RPMs [gated as CD11b-dim, F4/80-high, TREML4-high (Haldar et al., 2014); Fig. S2A and B] in aged mice exhibit a significant deficiency in $\mathrm{H}$ ferritin levels, with unchanged $\mathrm{L}$ ferritin protein expression (Fig. 1E and F). Consistently, using the fluorescent probe FerroOrange that interacts explicitly with ferrous iron, we detected a significant increase in LIP in aged RPMs (Fig. 1G) accompanied by marked oxidative stress (detected using CellROX probe; Fig. 1H). We next tested if this increase in labile iron in RPMs would impact the phagocytic activity. Hence, we incubated splenic single-cell suspension with temperature-stressed RBCs fluorescently labeled with PKH67 dye (Klei et al., 2020; Theurl et al., 2016). In parallel, we employed another standard cargo for phagocytosis, zymosan, a yeast cell wall component. Using this ex vivo approach, we detected a significant drop in RBCs clearance rate in aged compared to young RPMs (Fig. 1I). Notably, their capacity for the engulfment of zymosan remained unchanged (Fig. 1J), thus suggesting a specific defect of EP in aged RPMs. Using a probe that becomes fluorescent upon lysosomal degradation, we also 
bioRxiv preprint doi: https://doi.org/10.1101/2022.01.16.476518; this version posted January 19, 2022. The copyright holder for this preprint (which was not certified by peer review) is the author/funder, who has granted bioRxiv a license to display the preprint in perpetuity. It is made available under aCC-BY-ND 4.0 International license.

observed decreased lysosomal activity in RPMs isolated from 10-11-months old mice compared to those derived from young control animals (Fig. 1K). Finally, we found that RPMs of aged mice show diminished mitochondrial activity (using the TMRE probe to measure membrane potential; Fig. 1L). Interestingly, peritoneal macrophages of aged mice did not show altered labile iron or ROS levels, or diminished functions of lysosomes and mitochondria (Fig. S3), suggesting that these age-related changes affect RPMs earlier than other macrophage populations. Altogether, these insights suggest that during aging, RPMs increase LIP and exhibit the reduced capacity for the RBCs engulfment and lysosomal degradation of erythrocyte components.

A

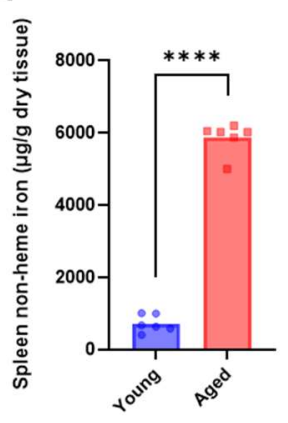

E

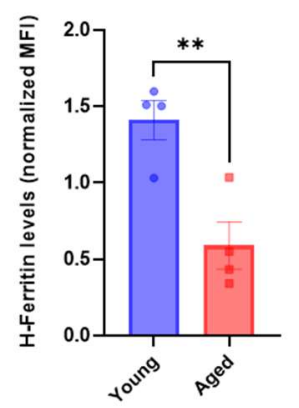

I

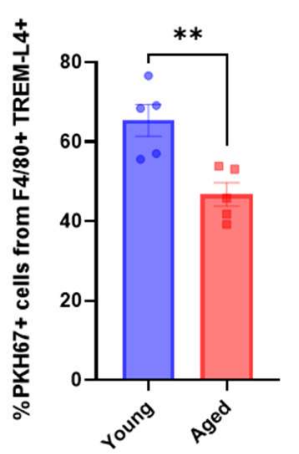

B

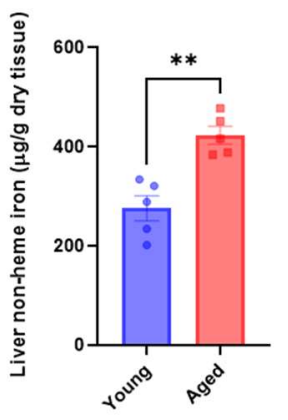

F

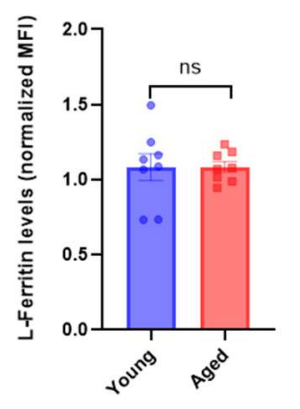

J

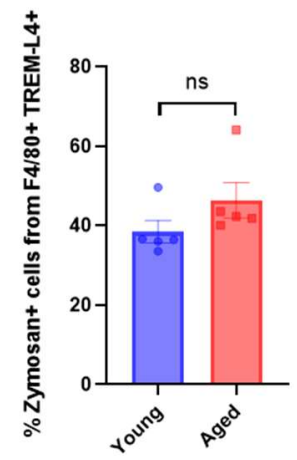

C

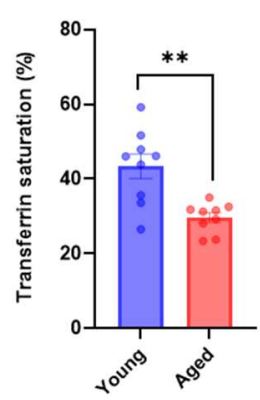

G

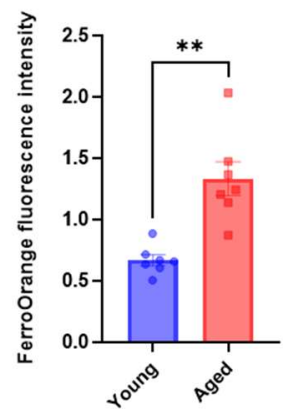

K

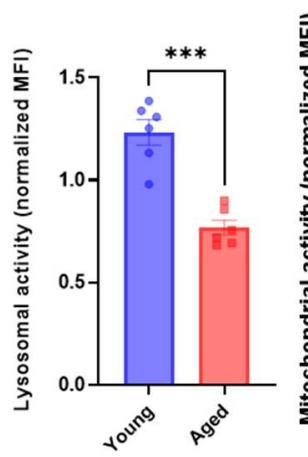

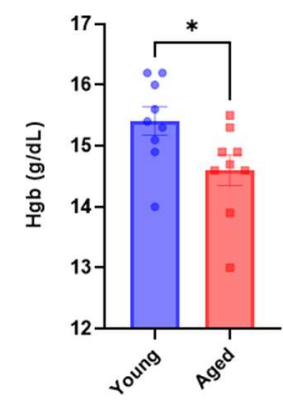

H

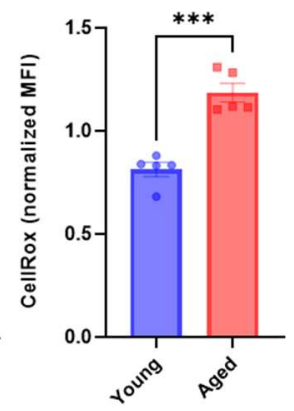

L

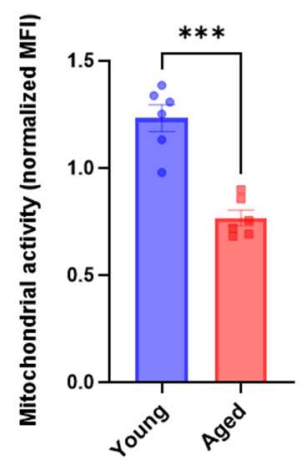

Figure 1. RPMs of aged mice show increased labile iron levels and diminished erythrophagocytic activity.

(A) Spleen and (B) liver non-heme iron content was determined in young and aged mice.

(C) Plasma transferrin saturation and (D) blood hemoglobin ( $\mathrm{Hgb}$ ) concentration were determined in young and aged mice.

(E) In young and aged RPMs, H-Ferritin and (F) L-Ferritin were quantified with flow cytometric analysis.

(G) Cytosolic ferrous iron (Fe2+) and (H) ROS levels in young and aged RPMs were quantified using FerroOrange and CellROX Deep Red with flow cytometry.

The phagocytosis rates of (I) PKH67-labeled temperature-stressed RBCs and (F) zymosan A fluorescent particles by young and aged RPMs were analyzed ex vivo by flow cytometry. The percent of cargo-positive RPMs is indicated.

(K) Lysosomal activity in young and aged RPMs was determined using a dedicated fluorescent probe and flow cytometry. 
bioRxiv preprint doi: https://doi.org/10.1101/2022.01.16.476518; this version posted January 19,2022 . The copyright holder for this preprint (which was not certified by peer review) is the author/funder, who has granted bioRxiv a license to display the preprint in perpetuity. It is made available under aCC-BY-ND 4.0 International license.

(L) The mitochondrial membrane potential in young and aged RPMs was measured by staining with TMRE and flow cytometry analysis.

Each dot represents one mouse. Data are represented as mean \pm SEM. Welch's unpaired t-test determined statistical significance between the two groups. ${ }^{*} p<=0.05,{ }^{* *} p<=0.01,{ }^{* * *} p<=0.001$ and $* * * * p<=0.0001$

Iron-reduced diet normalizes body iron parameters during aging, diminishes iron retention in RPMs, and prevents oxidative stress

We next set out to explore whether an age-related redistribution of iron from plasma to organs, particularly the spleen, could be prevented. Caloric restriction was previously shown to effectively reduce tissue iron content in older rats in organs such as muscle, kidney, liver, and brain (Cook and Yu, 1998; Xu et al., 2008). To target iron dyshomeostasis in aging mice, we applied an alternative approach by reducing dietary iron from the fifth week of life to a level $(25 \mathrm{ppm})$ that was reported as sufficient to maintain erythropoiesis (Sorbie and Valberg, 1974). We found that this approach reverted the degree of iron deposition in the spleen and liver (Fig. 2A and B) and tended to alleviate the decreased transferrin saturation characteristic of aged mice fed a standard diet (Fig. 2C). However, the mild drop in blood hemoglobin was not rescued by the iron-reduced (IR) diet (Fig. 2D). Consistently, extramedullary erythropoiesis in the spleen and increased plasma erythropoietin (EPO) levels that we observed in aged mice were not affected by dietary iron content (Fig. 2E and F and Fig. S). These observations imply that alleviation of plasma iron availability is insufficient in IR mice to correct mild anemia in our aging model and/or other hematopoiesis-related mechanisms contribute to this phenotype. Next, we observed that hepcidin mRNA levels in the liver reflected, as expected, the degree of hepatic iron deposition in mice that were aged on the standard and IR diets (Fig. 2G). The alterations in hepcidin expression levels were reflected by the changes of FPN levels on the surface of RPMs, as indicated by flow cytometry analyses using an antibody that recognizes the extracellular loop of murine FPN (Fig. 2H). Hence, we further characterized RPMs iron status. We found that despite decreased ferritin $\mathrm{H}$ levels in aged mice regardless of the dietary regimen (Fig. 2I), accumulation of both labile iron (measured using FerroOrange and flow cytometry; Fig. 2J) and total iron (measured by colorimetric assay in magnetically-sorted RPMs, Fig. 2K) is completely reversed in RPMs in aged mice fed an IR diet as compared to a standard diet. Likewise, we observed alleviation of oxidative stress in RPMs, both using a pan-ROS fluorescent probe CellROX (Fig. 2L) and specific detection of lipid peroxidation (Fig. S4A). Interestingly, we did not detect any alterations of ROS levels in mitochondria of aging RPMs (Fig. S4B). In sum, we demonstrated that dietary iron restriction normalizes both systemic and RPMs iron levels, thus preventing the onset of cellular oxidative stress in RPMs of aged mice. 
A

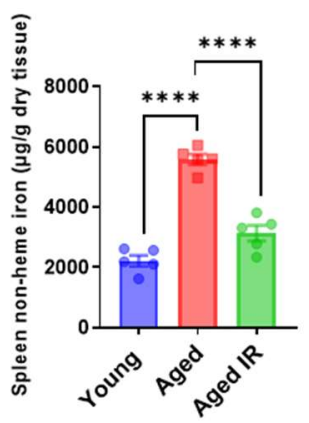

E

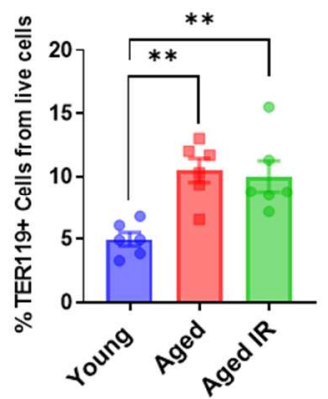

I

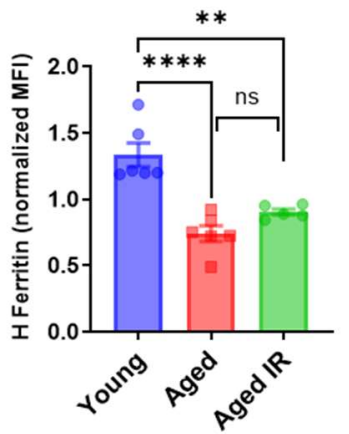

B

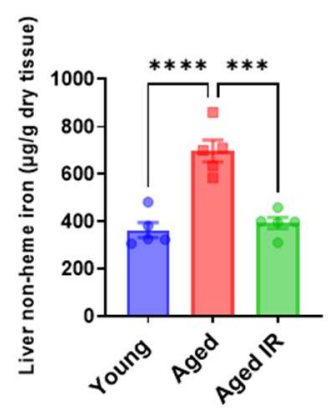

$\mathbf{F}$

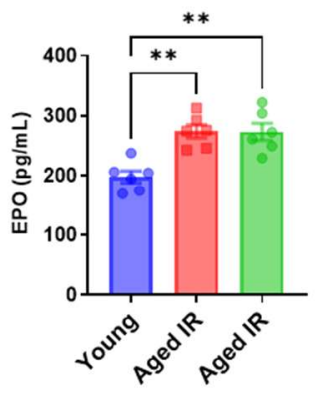

J

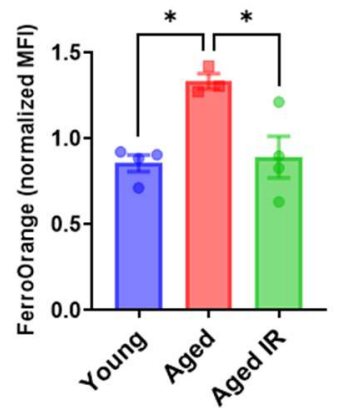

C

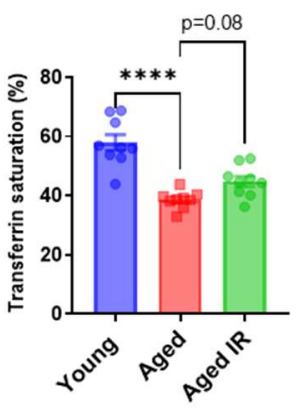

G

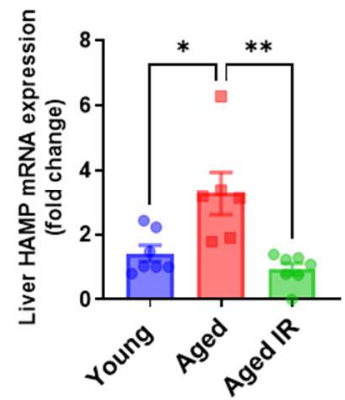

K

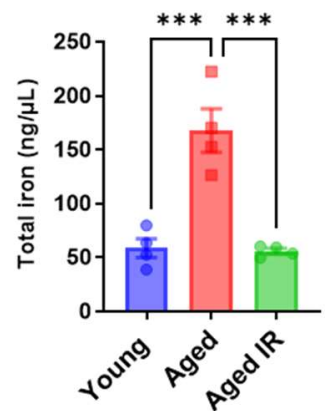

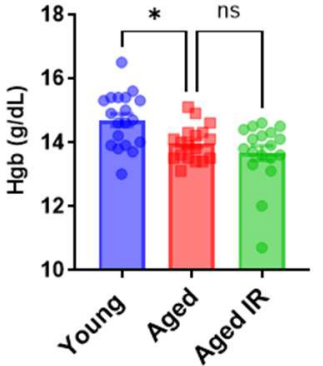

H

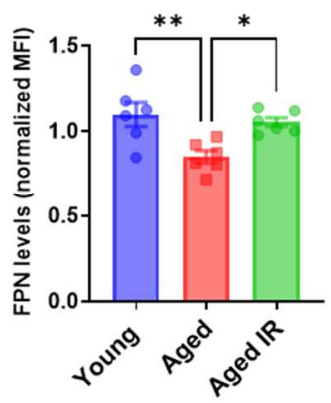

$\mathbf{L}$

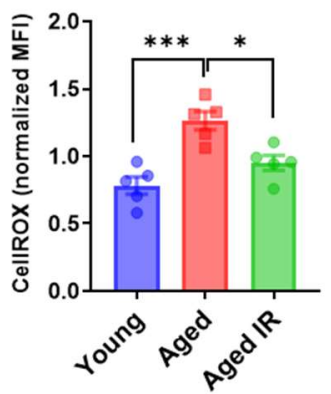

Figure 2. Iron-reduced diet normalizes body iron parameters during aging, diminishes iron retention in RPMs, and prevents oxidative stress.

(A) Splenic and (B) hepatic non-heme iron content was determined in young, aged, and aged IR mice.

(C) Plasma transferrin saturation and (D) blood hemoglobin ( $\mathrm{Hgb}$ ) concentration were determined in young, aged, and aged IR mice.

(E) Shown is the percentage of erythroid cells (TER119+) present in the spleen and (F) EPO concentration in the plasma of young, aged, and aged IR mice.

(G) Relative mRNA expression of hepcidin (Hamp) in the liver was determined by qPCR.

(H) Cell surface ferroportin expression in young, aged, and aged IR RPMs was assessed by flow cytometry.

(I) H-Ferritin protein levels in young, aged, and aged IR RPMs were quantified by flow cytometric analysis.

(J) Cytosolic ferrous iron (Fe2+) levels in young, aged, and aged IR RPMs were measured using FerroOrange and flow cytometry.

(K) The total intracellular iron content in young, aged, and aged IR magnetically-sorter RPMs was assessed using a commercial assay.

(L) The cytosolic ROS levels in young, aged, and aged IR RPMs were assessed by determining CellROX Deep Red fluorescence intensity with flow cytometry.

Each dot represents one mouse. Data are represented as mean \pm SEM. Statistical significance among the three groups was determined by the One-Way ANOVA test with Tukey's Multiple Comparison test. ${ }^{*} p<=0.05,{ }^{* *} p<=0.01,{ }^{* * *} p<=0.001$ and $* * * * p<=0.0001$ 
bioRxiv preprint doi: https://doi.org/10.1101/2022.01.16.476518; this version posted January 19,2022 . The copyright holder for this preprint (which was not certified by peer review) is the author/funder, who has granted bioRxiv a license to display the preprint in perpetuity. It is made available under aCC-BY-ND 4.0 International license.

\section{Iron-reduced diet rescues age-related decline in RPMs erythrophagocytosis capacity}

The major function of RPMs is the clearance of aged erythrocytes. We thus explored if their altered iron status in aged mice reflects their capacity to engulf and degrade RBCs. To this end, we first performed in vivo erythrophagocytosis assay via transfusion of PKH67-stained temperature-stressed erythrocytes (Lu et al., 2020; Theurl et al., 2016). We identified a significant reduction of the capacity of RPMs in aged mice to sequester RBCs, an impairment that was partially rescued by feeding mice an IR diet (Fig. 3A). Similarly to EP rate, we found that RPMs isolated from IR aged mice restored the lysosomal activity to the levels observed in young mice (Fig. 3B). These data imply that the diminished capacity of RPMs to sequester and lyse RBCs during aging can be ameliorated by limiting dietary iron content. Likewise, we observed that decreased mitochondrial activity of RPMs in aged mice, and to a lesser extent, the mitochondria mass (measured with the MitoTracker probe), are alleviated by an IR diet (Fig. 3C and D). This corresponds to higher ATP levels in FACS-sorted RPMs derived from aged mice fed an IR diet compared to the standard diet (Fig. 3E). Since earlier studies demonstrated that under conditions of RPMs impairment, iron-recycling functions are significantly supported by liver macrophages ( $\mathrm{Lu}$ et al., 2020; Theurl et al., 2016), we also measured their EP rate during aging. Using the transfusion of PKH67-stained RBCs (Akilesh et al., 2019) we found no increase in Kupffer cells (KCs) EP capacity in mice fed IR (Fig. 3F). However, consistently with the de novo recruitment of ironrecycling myeloid cells to the liver upon erythrocytic stress (Theurl et al., 2016), we detected a significant expansion of the KC-like population in aged mice (Fig. 3G), but not in the aged IR group (Fig. $3 \mathrm{H}$ ), suggesting that by this means, the liver macrophage may partially compensate for the reduced EP activity in RPMs. In support of the model that 'on-demand' hepatic iron-recycling macrophages support iron recycling during aging, and in agreement with the previous findings that iron from engulfed RBCs is stored in hepatocytes (Theurl et al., 2016), we observed progressive liver iron accumulation with age (Fig. 3I). In conclusion, our data indicate that reduced iron supplementation has a protective effect on RPMs, rescuing age-related decline in their EP capacity. 
A

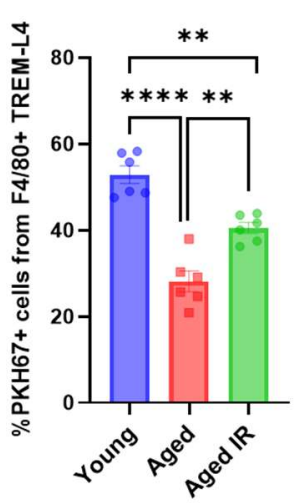

D

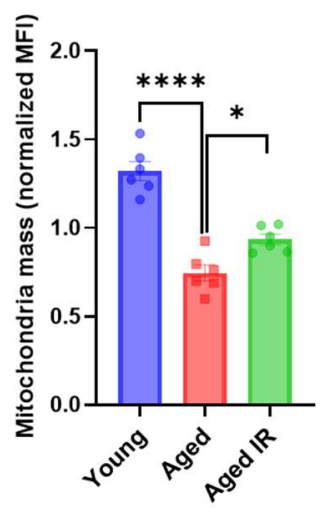

G
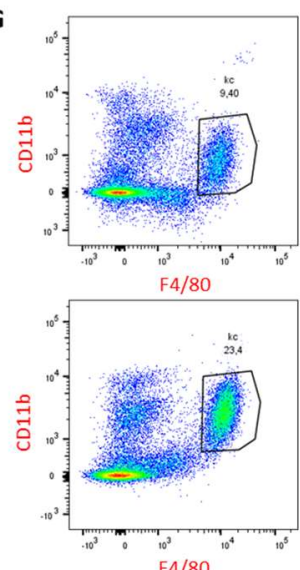

B

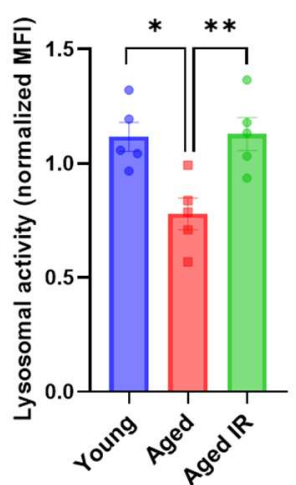

E

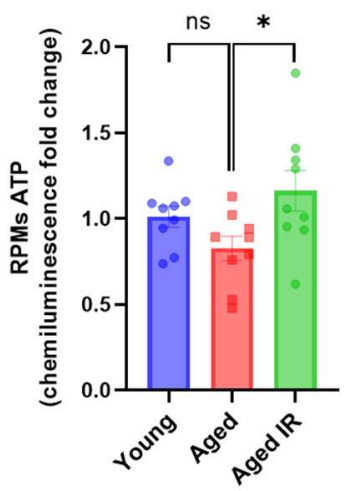

H

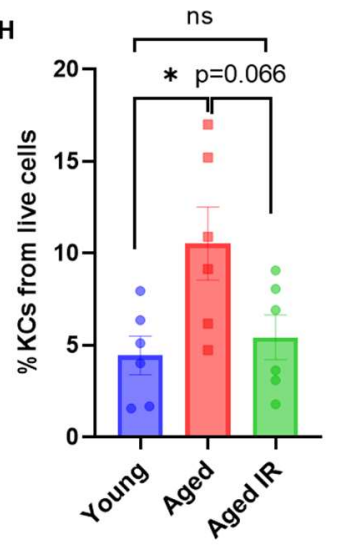

C

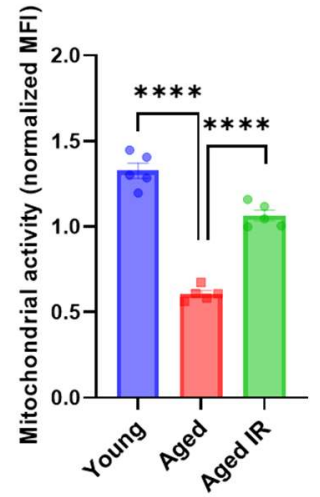

$\mathbf{F}$

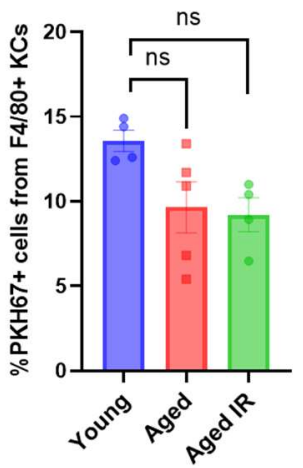

I

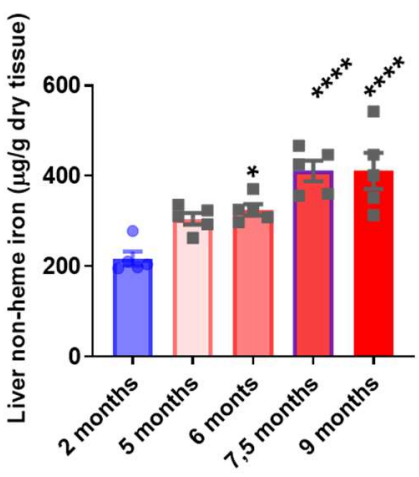

Figure 3. Iron-reduced diet rescues RBCs clearance capacity of RPMs.

(A) RBC clearance capacity in young, aged, and aged IR RPMs was determined by measuring the percentage of RPMs that phagocytosed transfused PKH67-labeled temperature-stressed RBCs.

(B) Lysosomal activity of young, aged, and aged IR RPMs was determined using a dedicated fluorescent probe and flow cytometry.

(C) The mitochondrial membrane potential and (D) mitochondrial mass in RPMs isolated from young, aged, and aged IR mice were measured by staining with TMRE and MitoTracker Green, respectively, and analyzed by flow cytometry.

(E) Levels of ATP in FACS-sorted RPMs isolated from young, aged, and aged IR.

(F) The phagocytosis rate of PKH67-labeled temperature-stressed RBCs by Kupffer cells (KCs) in young, aged, and aged IR mice measured with flow cytometry analysis.

(G) Representative flow cytometry plots of KCs in young and aged mice.

(H) Percentages of KCs out of total live cells in livers of young, aged, and aged IR mice.

(I) Liver non-heme iron content was determined in mice at the indicated age.

Each dot represents one mouse. Data are represented as mean \pm SEM. Statistical significance among the three or more groups was determined by One-Way ANOVA test with Tukey's Multiple Comparison test. ${ }^{*} p<=0.05,{ }^{*} p<=0.01,{ }^{* * *} p<=0.001$ and $* * * * \mathrm{p}<=0.0001$ 


\section{Iron-reduced diet partially rescues age-triggered retention of senescent $\mathrm{RBCs}$ in the spleen}

Having established that dietary iron content in aging modulates RPMs EP capacity (Fig. 3A), we examined parameters related to RBCs fitness. First, we performed an RBCs lifespan assay and found no differences in the rate of RBCs removal from the circulation between young and aged mice (Fig. 4A). However, defective RBCs are first filtered in the spleen due to the loss of their elasticity, and this step is a prerequisite for their removal via EP (Slusarczyk and Mleczko-Sanecka, 2021). In agreement with this model, RBCs that are retained in the spleen of young mice show ROS build-up, a marker of their senescence (Bratosin et al., 1998), compared to the circulating RBCs (Fig. 4B and S5). We thus hypothesized that reduced phagocytic capacity of RPMs in aging might impact local rather than systemic RBCs homeostasis. Consistently, splenic RBCs isolated from older mice show more pronounced ROS levels than RBCs derived from young mice (Fig. 4C and F). In line with the partial mitigation of the defective EP capacity (Fig. 3A), we found that mice fed an IR diet exhibited erythrocytic oxidative stress parameters as the young mice (Fig. 4D). Since ROS can accumulate in RBCs with deficient FPN (Zhang et al., 2018), we examined FPN levels of splenic RBCs. We found no reduction but a significant FPN increase in aged mice, implying that increased erythrocytic ROS are not caused by alterations in FPN levels (Fig. 4E). Furthermore, in agreement with the notion that a part of senescent splenic RBCs undergoes hemolysis (Klei et al., 2020), we detected significantly higher levels of extracellular heme in the aged spleens, likely reflecting a higher burden of defective RBCs that escape EP (Fig. 4F). Interestingly, we found that the levels of this free heme in aging spleens tend to be rescued by the IR diet (Fig. 4F). In conclusion, our data suggest that reduced EP rate during aging may promote the retention of senescent RBCs prone to undergo local lysis and that these physiological changes may be partially rescued by maintaining mice on an IR diet. 


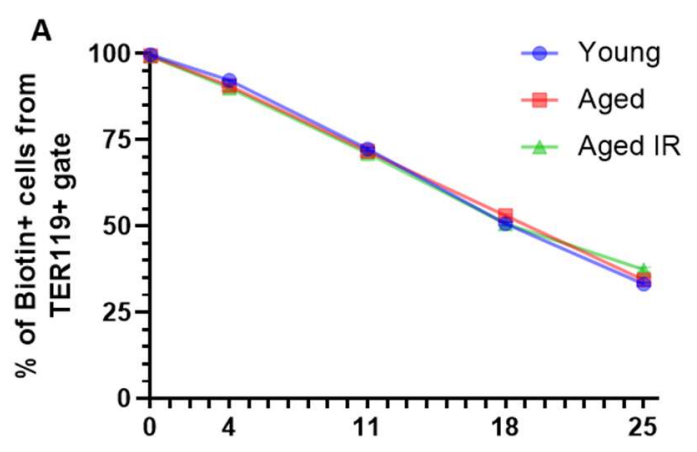

B

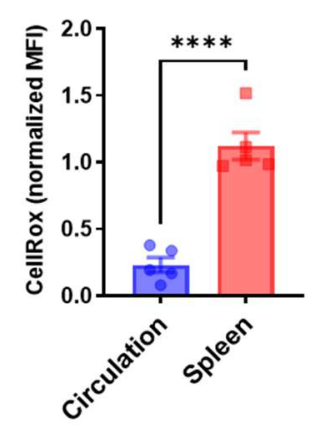

C

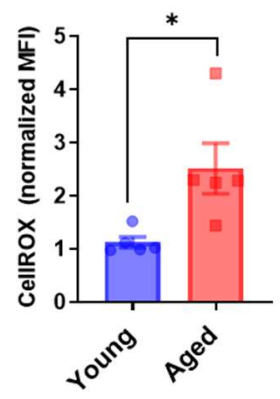

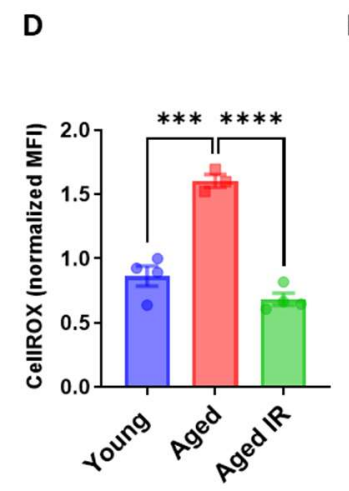

$\mathbf{E}$

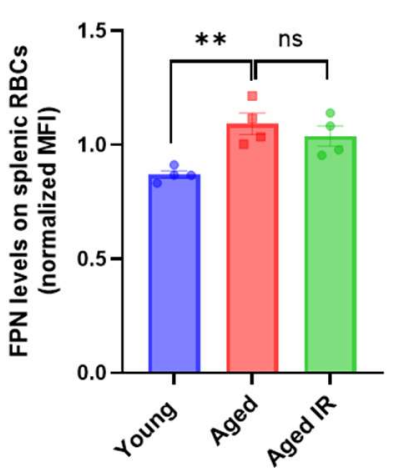

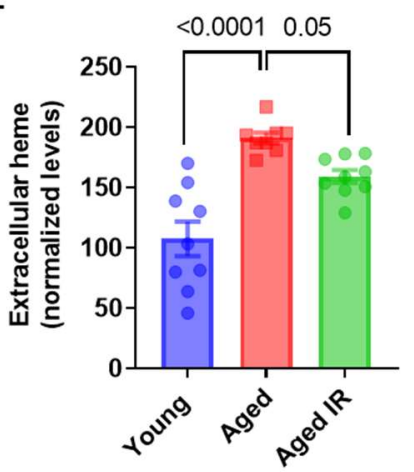

Figure 4. Iron-reduced diet partially rescues age-triggered retention of senescent RBCs in the spleen.

(A) The RBC biotinylation assay was performed on circulating RBCs from young, aged, and aged IR mice. Biotinylated RBCs were detected by flow cytometry.

(B-D) The cytosolic ROS levels in RBCs derived from (B) circulation and the spleen of young mice; (C) the spleen of young and aged mice; (D) the spleen of young, aged, and aged IR mice. Levels of ROS were estimated by determining CellROX Deep Red fluorescence intensity with flow cytometry.

(E) Expression of ferroportin on the surface of RBCs obtained from the spleen of young, aged, and aged IR mice assessed by flow cytometry.

(F) Extracellular heme levels were measured in the medium obtained after dissociation of spleens from young, aged, and aged IR mice using Heme Assay Kit.

Each dot in graph (A) represents $n=8$. For the other panels, each dot represents one mouse. Data are represented as mean \pm SEM. Welch's unpaired t-test determined statistical significance between the two groups; for the three groups, One-Way ANOVA with Dunnett's or Tukey's Multiple Comparison test was applied. ${ }^{*} p<=0.05,{ }^{*} p<<=0.01,{ }^{* * *} p<=0.001$ and $* * * * p<=0.0001$

\section{Age-triggered decrease in erythrophagocytic capacity of RPMs drives the formation of non-} degradable iron-rich splenic aggregates

Previous work showed that genetic deletion of SPI-C, the transcription factor that confers RPMs functional identity (Haldar et al., 2014; Kohyama et al., 2009), leads to the gradual loss of RPMs in young postnatal mice (Okreglicka et al., 2021). The knock-out of Pparg, a factor required for neonatal RPM expansion, is manifested by a profound depletion of RPMs (Okreglicka et al., 2021), whereas low numbers of fully differentiated RPMs manifest the genetic abrogation of the IL-33-IL1RL1 pathway with compromised EP capacity (Lu et al., 2020). A common denominator for all these distinct mouse models is iron accumulation in the spleen, hallmarked by elevated non-heme iron levels and the presence of ferric iron deposits as indicated by Perls' staining. Thus, these previous reports imply that splenic 
iron overload may result from diminished RPMs functionality. In support of this scenario, we observed that RPMs reduce their capacity for EP with age progression (Fig. 5A) in a manner that reflects the kinetics of splenic non-heme iron loading (Fig. 5B). We next aimed to explore the identity of splenic iron deposits in more detail. Perls' staining of spleen sections showed that aged mice on a standard diet exhibit enhanced iron accumulation in the red pulp, a less pronounced phenotype in mice fed an IR diet (Fig. 5C). This primarily reflects RPMs iron status (Fig. 2J and K). We also detected large iron-loaded cells in the white pulp of aged mice fed a standard diet that were absent in iron-reduced mice (Fig. 5C). Intriguingly, eosin/hematoxylin staining visualized additional, presumably extracellular, deposits in aged spleens that were absent in young controls and less abundant in mice fed an IR diet (Fig. 5D). Consistently, flow cytometry analyses revealed that splenic single-cell suspension from aged but not young mice contains superparamagnetic particles, likely rich in iron oxide (Franken et al., 2015) that do not show staining indicative of dead cells and fail to express typical splenocyte and erythroid markers (CD45, TER119, CD11b or F4/80) (Fig. 5E). With different granularity and size parameters, such particles appear as well in mice aged on an IR diet, however, to a lesser extent. We established a strategy involving splenocyte separation in the lymphocyte separation medium followed by magnetic sorting, which successfully separates iron-rich cells (chiefly RPMs) from iron-containing extracellular aggregates (Fig. S6). We found that these aggregates contain large amounts of total iron (Fig. 6F) and heme-iron (Fig. 6G), the levels of which are significantly reduced in mice fed an IR diet. Preliminary proteomic profiling identified $\mathrm{L}$ and $\mathrm{H}$ ferritins, $\alpha$ and $\beta$ globins, and lysosomal components, among the top 30 proteins detected in the aggregates (data not shown), suggesting that they likely represent protein debris of both damaged RBCs and RPMs. These data suggest that age-related deposition of RBC-derived extracellular iron in the spleen due to impaired RPMs function limits the bioavailability of iron for further systemic utilization. 
bioRxiv preprint doi: https://doi.org/10.1101/2022.01.16.476518; this version posted January 19, 2022. The copyright holder for this preprint (which was not certified by peer review) is the author/funder, who has granted bioRxiv a license to display the preprint in perpetuity. It is made available under aCC-BY-ND 4.0 International license.
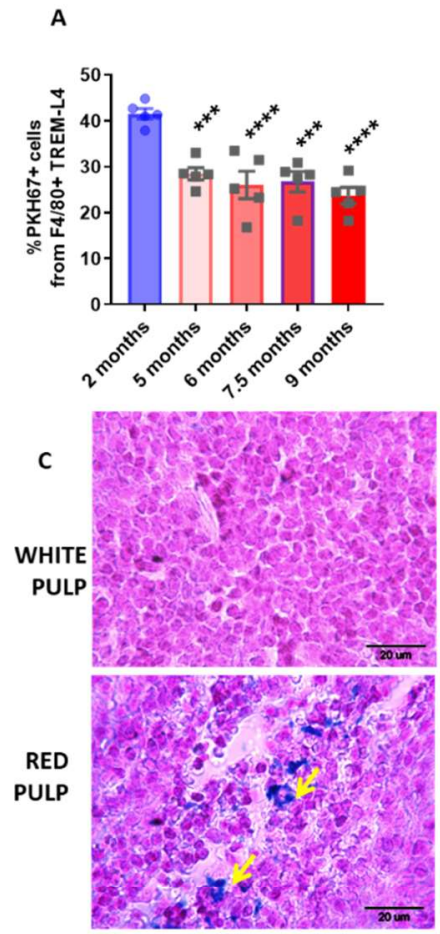

D

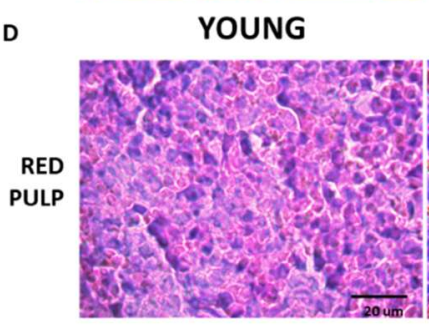

E

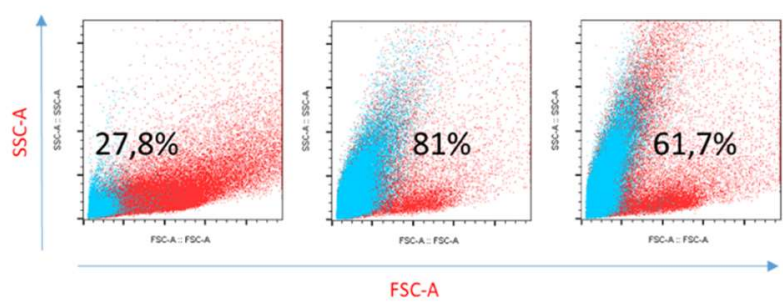

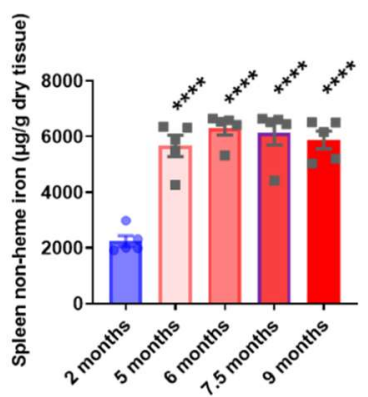

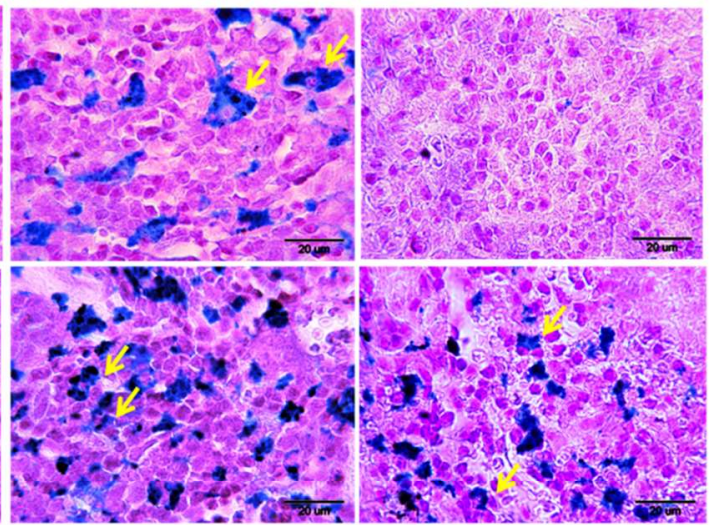

AGED

AGED IR

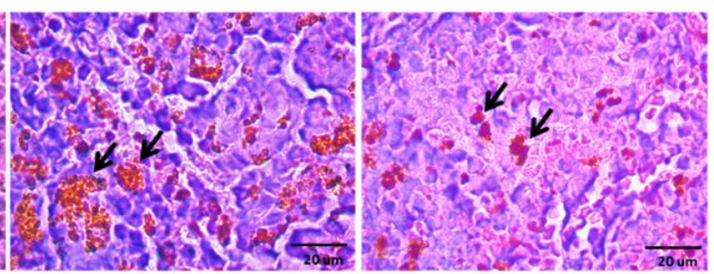

$\mathbf{F}$

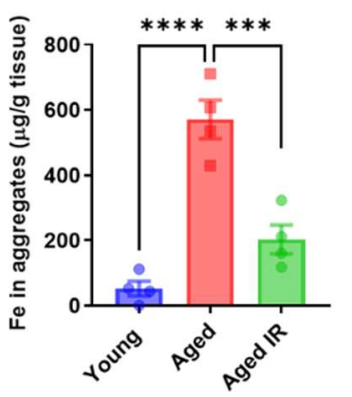

G

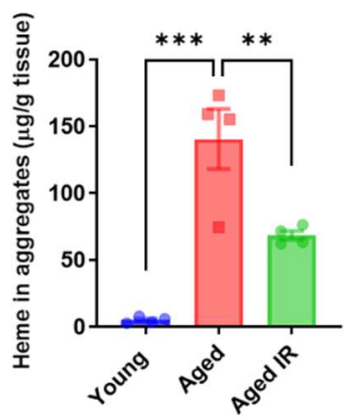

Figure 5. Age-triggered decrease in erythrophagocytic capacity drives the formation of extracellular iron-rich aggregates. (A) RBC clearance capacity of RPMs in mice at the indicated age was determined by measuring the percentage of RPMs that phagocytosed transfused PKH67-labeled temperature-stressed RBCs.

(B) Spleen non-heme iron content was determined in mice at the indicated age.

(C) Perls' Prussian Blue staining of the splenic white and red pulp in young, aged, and aged IR mice. Arrows indicate ferric iron deposits.

(D) Hematoxylin and eosin staining of the splenic red pulp in young, aged, and aged IR mice. Arrows indicate extracellular brown aggregates.

(E) Representative flow cytometry plots of magnetically-sorted splenocytes. In blue are events adverse for dead cell staining and cell surface markers CD45, TER119, CD11b, and F4/80. The percentage of these events in total acquired events is indicated.

(F) The total iron content in magnetically-sorted, cell-free aggregates derived from spleens of young, aged, and aged IR RPMs mice was assessed using a commercial assay.

(G) The heme content in magnetically-sorted, cell-free aggregates derived from spleens of young, aged, and aged IR RPMs mice was assessed using Heme Assay Kit. 
bioRxiv preprint doi: https://doi.org/10.1101/2022.01.16.476518; this version posted January 19, 2022. The copyright holder for this preprint (which was not certified by peer review) is the author/funder, who has granted bioRxiv a license to display the preprint in perpetuity. It is made available under aCC-BY-ND 4.0 International license.

Each dot represents one mouse. Data are represented as mean \pm SEM. Statistical significance among the three or more groups was determined by One-Way ANOVA test with Tukey's Multiple Comparison test. ${ }^{*} p<=0.05, * * p<=0.01, * * * p<=0.001$ and $* * * \mathrm{p}<=0.0001$

\section{Labile iron retention, but not oxidative stress or diminished mitochondrial function of RPMs suppresses erythrophagocytosis}

The contribution of iron deposition to age-related deterioration of cellular functions is believed to be primarily mediated by the pro-oxidative properties of labile iron (Xu et al., 2008). We observed a clear indication of oxidative stress in aging RPMs (Fig. 2L) that was rescued by the IR diet. Next, we aimed to verify whether the increased ROS levels solely contribute to diminished phagocytic and cellular functions of RPMs during aging. To this end, we supplemented aging mice with antioxidant N-AcetylL-cysteine (NAC), which was previously shown to revert aging-related physiological changes (Berman et al., 2011; Ma et al., 2016). With this strategy, we reduced oxidative stress in aged RPMs (Fig. 6A) without affecting spleen iron loading (Fig. 6B). Importantly, we did not observe an improvement in the reduced rate of EP in RPMs isolated from NAC-supplemented mice compared to control aged mice (Fig. 6C). This suggests that the ability of RPMs to remove RBCs is likely affected by iron loading rather than excessive ROS. In support of this, we also detected an increase in RPMs labile iron with age progression (Fig. 6D), reflecting a drop in EP (Fig. 5A). To follow this possibility, we next employed a cellular model of bone marrow-derived macrophages, exposed to hemin and IL-33, two factors that drive RPMs differentiation (Haldar et al., 2014; Lu et al., 2020) and induce RPM-like transcriptional signatures ( $\mathrm{Lu}$ et al., 2020). We noted that these cells that we termed 'induced RPMs (iRPMs)' significantly decrease their EP activity upon iron overloaded with ferric ammonium citrate (FAC) in a manner that is partially rescued by the iron chelator DFO (Fig. 6E). Interestingly, adding the same dose of hemin as FAC did not significantly alter the rate of RBCs uptake by iRPMs, suggesting a low sensitivity of the phagocytic system of these cells to excessive heme (Fig. 6E). We also found that the drop in EP did not reflect the level of mitochondria activity. Mitochondria membrane potential was similarly diminished by FAC, hemin, and DFO alone, thus uncoupling the phagocytic activity of iRPMs from their mitochondria fitness (Fig. 6F). Furthermore, we observed that iron loading by FAC, but not hemin, suppresses lysosomal activity (Fig. 6G). In sum, our data indicate that iron loading of iRPMs perturbs both EP capacity and lysosomal functionality and may reflect the physiological status of aging mouse RPMs. 
A

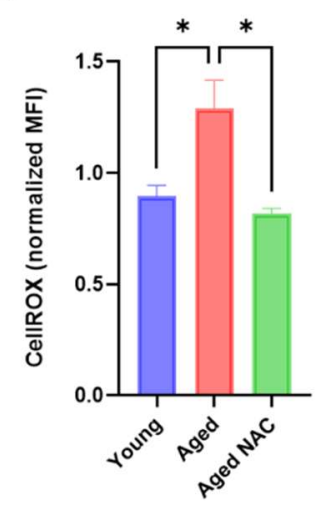

D
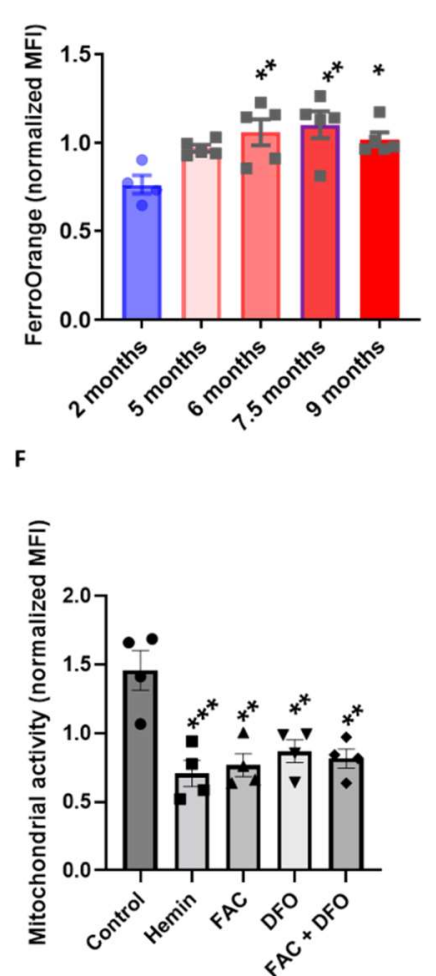

B

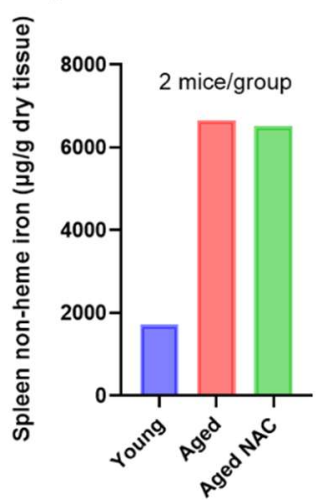

E
C

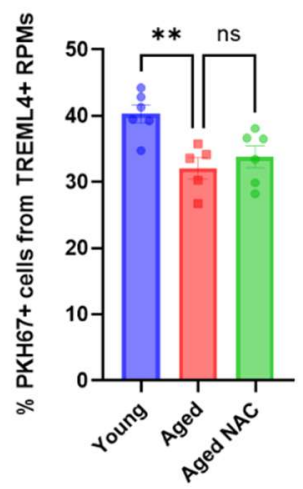

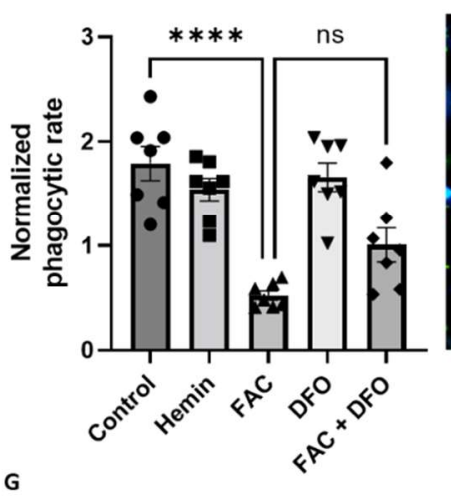

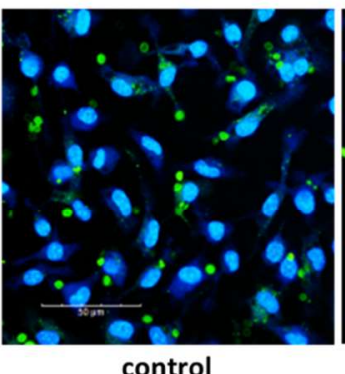

control

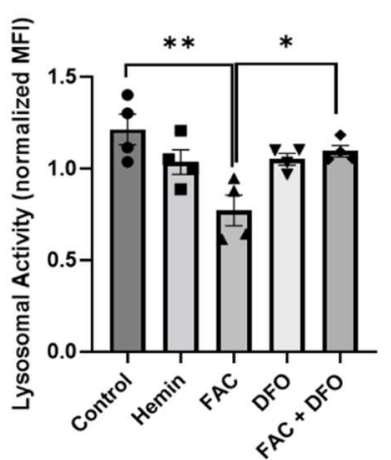

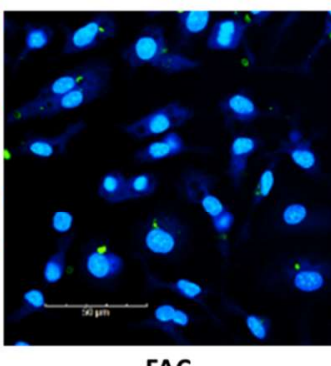

FAC

Figure 6. Labile iron retention, but not oxidative stress or diminished mitochondrial function of RPMs, suppresses erythrophagocytosis.

(A) The cytosolic ROS levels in RPMs derived from young, aged, and aged NAC were assessed by determining CellROX Deep Red fluorescence intensity with flow cytometry.

(B) Spleen non-heme iron content was determined in young, aged, and aged NAC.

(C) RBC clearance capacity of RPMs derived from young, aged, and aged NAC mice was determined by measuring the percentage of RPMs that phagocytosed transfused PKH67-labeled temperature-stressed RBCs.

(D) Cytosolic ferrous iron (Fe2+) content in RPMs isolated from mice at the indicated age was measured using FerroOrange and flow cytometry.

(E) Normalized phagocytic rate of PKH67-labeled temperature-stressed RBCs by cultured iRPMs. Cells were treated with FAC $(50 \mu \mathrm{M}, 24 \mathrm{~h})$, hemin $(50 \mu \mathrm{M}, 24 \mathrm{~h})$, or DFO $(100 \mu \mathrm{M}, 18 \mathrm{~h})$ as indicated. Representative confocal microscopic images of erythrophagocytosis in FAC-treated iRPMs compared with controls are shown on the right.

(F) Mitochondrial and (G) lysosomal activity of cultured iRPMs were determined using dedicated fluorescent probes and flow cytometry. Cells were treated with FAC (50 $\mu \mathrm{M}, 24 \mathrm{~h})$, hemin $(50 \mu \mathrm{M}, 24 \mathrm{~h})$, or DFO $(100 \mu \mathrm{M}, 18 \mathrm{~h})$ as indicated.

Each dot represents one mouse or independent cell-based experiment. Data are represented as mean \pm SEM. Statistical significance among the three or more groups was determined by One-Way ANOVA test with Dunnett's or Tukey's Multiple Comparison test. ${ }^{*} p<=0.05,{ }^{*} p<=0.01,{ }^{* * *} p<=0.001$ and ${ }^{* * * *} p<=0.0001$ 
bioRxiv preprint doi: https://doi.org/10.1101/2022.01.16.476518; this version posted January 19, 2022. The copyright holder for this preprint (which was not certified by peer review) is the author/funder, who has granted bioRxiv a license to display the preprint in perpetuity. It is made available under aCC-BY-ND 4.0 International license.

\section{Impaired heme metabolism, ER stress, and iron loading jointly undermine the ability of aging RPMs to erythrophagocytose}

Our data so far imply that iron accumulation in RPMs suppresses EP (Fig. 2J and K; 3A and 6E). However, complete restoration of iron status in RPMs of aging mice by IR diet does not fully recover EP activity. To further understand the molecular mechanisms that influence RPMs dysfunction during aging, we performed RNA sequencing of FACS-sorted RPMs from young and aged mice. We identified 570 differentially expressed genes, including 392 up- and 178 down-regulated transcripts (Fig. S7A). Interestingly, only 54 genes were found differentially regulated between mice fed a standard and IR diet (Fig. S7B), implying that functional changes between these groups are largely based on protein activity and/or post-transcriptional changes. Functional enrichment analysis revealed that aged RPMs, regardless of the dietary regimen, are hallmarked by ER stress, unfolded protein response (UPR), and ER-associated degradation (ERAD) (Fig. 7A and S7C). ERAD is a pathway for targeting misfolded ER proteins for cytoplasmic proteasomal degradation (Qi et al., 2017). Correspondingly, we identified a significant increase in proteasomal activity in aged RPMs, measured with a dedicated fluorescent probe that undergoes proteasomal cleavage (Fig. 7B). The IR diet rescued this phenomenon, suggesting links with iron/oxidative stress-related factors and potentially a compensatory response to the diminished lysosomal-mediated proteostatic control (Fig. 3B). Furthermore, our RNA-seq data revealed that one of the transcripts that significantly decreases in aged RPMs independent of diet is Hmox-1, which encodes HO-1 (Fig. S6A). We validated this result using intracellular staining and flow cytometry, and uncovered a marked decrease in HO-1 protein level in aged RPMs (Fig. 7C), which seem to progress over time between 5 to 9 months of age (Fig. 7D). Next, we tested how pharmacological blockage of HO-1 in iRPMs affects EP rate. Interestingly, exposure of iRPMs to zinc protoporphyrin (ZnPP), an HO-1 inhibitor, substantially diminished their ability to capture RBCs (Fig. 7E). However, RPMs from aging mice show similar ER stress and HO-1 levels irrespective of diet and differ primarily in iron status (Fig. $2 \mathrm{~K}$ and $\mathrm{L}$ ). Therefore, we next tested how the combination of a relatively low dose of ZnPP $(0.5$ $\mu \mathrm{M})$ and the ER stress inducer tunicamycin with a mild FAC exposure $(10 \mu \mathrm{M})$ affects EP in cellulo. We uncovered that these factors additively suppress the phagocytosis of RBCs (Fig. 7F). and likely collectively contribute to the rescue capacity of the IR diet, which reduces iron content in aged RPMs (Fig. 2J and K). Finally, we explored why ZnPP, but not hemin alone, suppresses EP. We speculated that possibly another co-product of HO-1 enzymatic activity, such as $\mathrm{CO}$ or biliverdin (Gozzelino et al., 2010), counterbalances the suppressive effect of iron release after EP. Thus, we tested whether the effect of $\mathrm{ZnPP}$ on EP can be rescued by supplementation of cells with CO donor CORMA1 or biliverdin. Interestingly, we found that CORMA1, but not biliverdin, rescues EP rate under ZnPP exposure in iRPMs (Fig. 7G and H), implying that $\mathrm{CO}$ acts as a modulator of EP activity in RPMs. In summary, our data indicate that impaired heme metabolism in concert with iron deposition and ER stress attenuates the potential of aging RPMs for RBC clearance. 
A

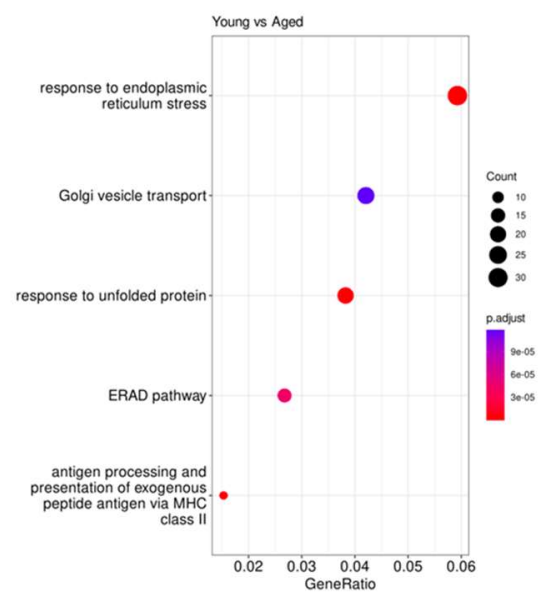

C

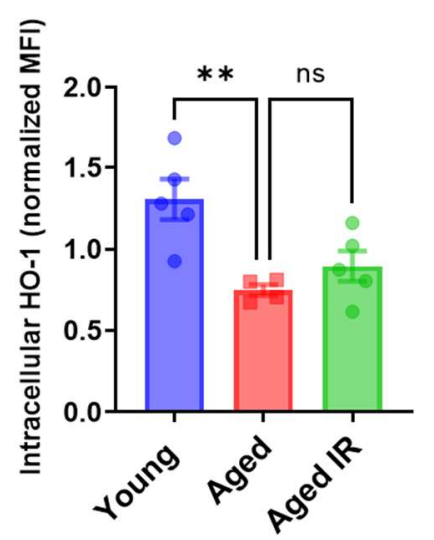

$\mathbf{F}$

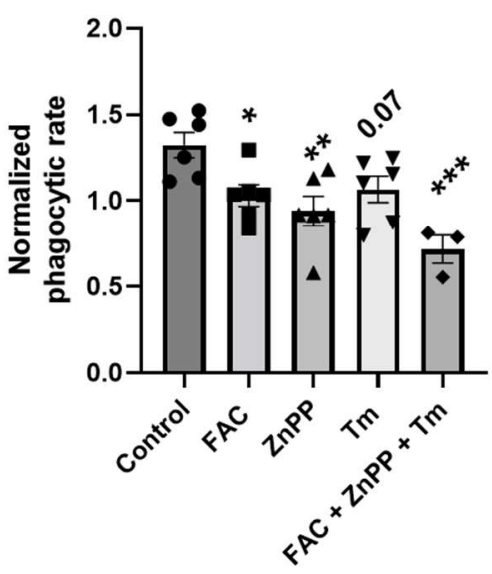

B

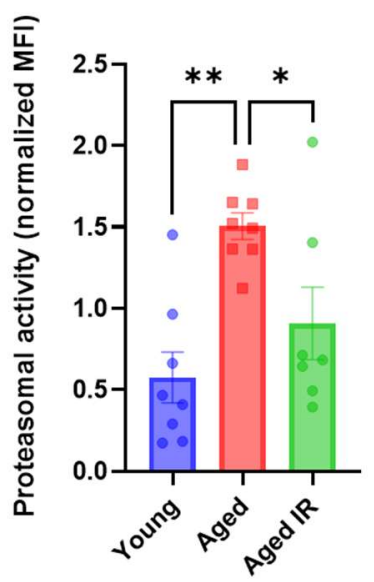

E

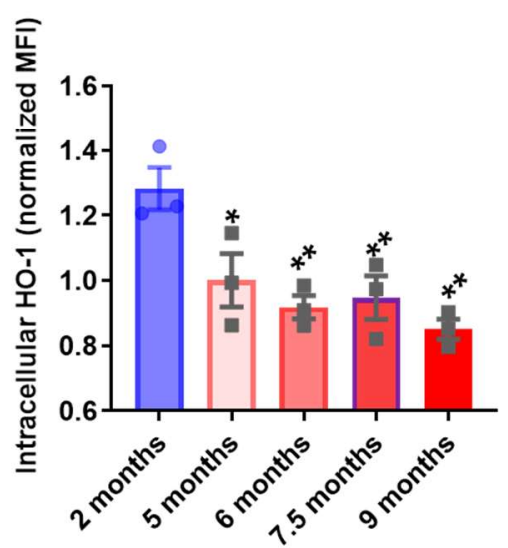

G

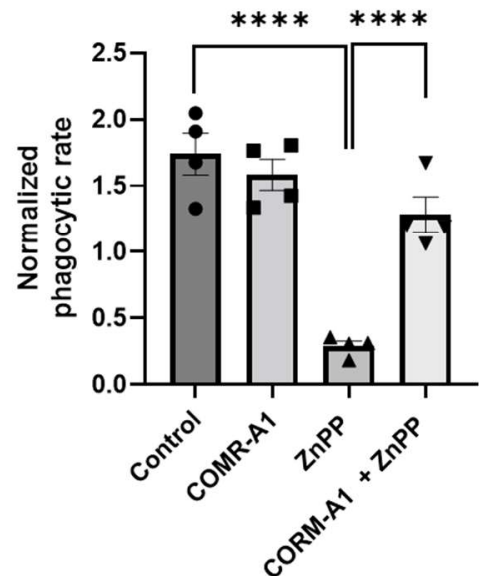

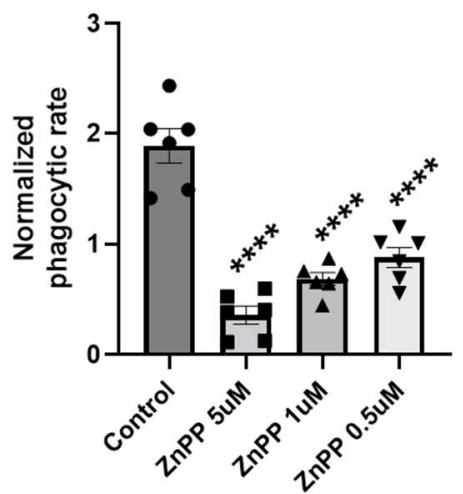

H

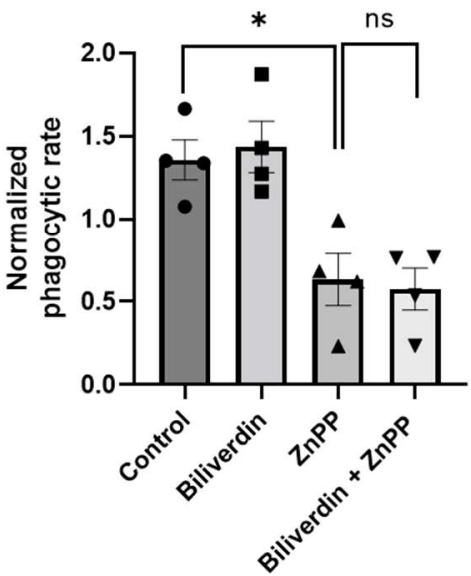

Figure 7. Diminished activity of HO-1 suppresses erythrophagocytosis additively with iron loading and ER stress.

(A) Enriched functional categories among differentially regulated genes in FACS-sorted RPMs derived from young versus aged mice (identified by RNA-seq).

(B) Proteasomal activity measured in RPMs isolated from young, aged, and aged IR mice using a dedicated fluorescent probe and flow cytometry.

(C) Intracellular HO-1 protein levels in RPMs isolated from young, aged, and aged IR mice.

(D) Intracellular HO-1 protein levels in RPMs isolated from mice at the indicated age. 
(E) Normalized phagocytic rate of PKH67-labeled temperature-stressed RBCs by cultured iRPMs. Cells were treated with indicated concentrations of ZnPP, an HO-1 inhibitor, for $24 \mathrm{~h}$.

(F) Normalized phagocytic rate of PKH67-labeled temperature-stressed RBCs by cultured iRPMs. Cells were treated with indicated low concentrations of $\mathrm{ZnPP}(0,5 \mu \mathrm{M})$ and FAC $(10 \mu \mathrm{M})$ and with ER stress inducer Tunicamycin (Tm; $2,5 \mu \mathrm{M})$ for 24 h.

( $G$ and $H$ ) Normalized phagocytic rate of PKH67-labeled temperature-stressed RBCs by cultured iRPMs. Cells were treated with ZnPP $(5 \mu \mathrm{M})$ and $(\mathrm{G})$ CORMA1 $(50 \mu \mathrm{M})$ or $(\mathrm{H})$ Biliverdin $(50 \mu \mathrm{M})$.

\section{Discussion}

RPMs play an essential role in preventing the release of hemoglobin from RBCs and maintaining the internal recycling of the body iron pool (Slusarczyk and Mleczko-Sanecka, 2021). To date, impairments of their functions have been reported in genetically modified mice. These include models with an almost complete or partial loss of RPMs due to the absence of genes that control RPMs differentiation, such as Pparg, Spi-c, Il-33, or its receptor Il1rll (Kohyama et al., 2009; Lu et al., 2020; Okreglicka et al., 2021). The common hallmark of defective iron-recycling functions in these mice is iron accumulation in the spleen. In contrast, in Hmox-1-deleted mice that cannot metabolize heme and are severely deficient in RPMs, splenic ferric iron deposits are depleted (Kovtunovych et al., 2010). Finally, genetic disruption of $\mathrm{Hrg}$-1, a transporter that delivers RBC-derived heme to the cytoplasm, leads to the formation of heme aggregate hemozoin inside enlarged phagolysosomes of RPMs (Pek et al., 2019). Here, we provide, for the first time, evidence that the defective RPMs' capacity for RBC clearance and phagolysosomal degradation accompanies physiological aging, a phenomenon that can be mitigated by reducing dietary iron.

Since the unique architecture of the spleen confers a filter for verifying the biomechanical integrity of RBCs (Mebius and Kraal, 2005; Slusarczyk and Mleczko-Sanecka, 2021), we observed only local but not systemic dyshomeostasis of RBCs during aging. Most importantly, we found that splenic RBCs of aged mice show ROS accumulation, a characteristic feature of senescent RBCs, and a risk factor for enhanced hemolysis (Zhang et al., 2018). Recent insights suggest that iron recycling in the spleen is driven by an equilibrium between phagocytosis and natural hemolysis of RBCs (Klei et al., 2020). Our study implies that in aging this balance is likely shifted towards the destruction of senescent RBCs. It remains to be investigated whether the exposure of the splenic microenvironment to excessive heme due to the enhanced breakdown of RBCs may affect the function of other cells that traffic and reside in the spleen, such as lymphocytes.

The present study provides, what we believe, is new evidence for the origin of iron deposits in the aging spleen. Our data imply that RPMs dysfunction contributes to the formation of non-cellular iron- and heme-rich protein aggregates. These molecules have a large size and are characterized by the presence of about 1000 proteins, which distinguishes them from hemozoin or lipofuscin, that form in lysosomes (Kurz et al., 2011; Pek et al., 2019). However, we cannot exclude the possibility that these two polymerlike structures may contribute to the formation of iron aggregates that contain large amounts of ferritin, globin chains, lysosomal proteins, and nuclear components, probably derived from both damaged RBCs 
and RPM. The exact mechanism and kinetics of their formation would require further investigation, but unequivocally it emphasizes the dysfunction of RPMs in the aged spleen. We propose that the build-up of these un-degradable iron particles, in concert with increased hepcidin levels, limits plasma iron availability during aging. These age-related changes are rescued, although to a different extent, by the IR diet. Hence, to the best of our knowledge, this study provides novel and mechanistic insights into why reducing dietary iron improves distinct but interconnected parameters of iron dyshomeostasis in aging. Future studies may be needed to design strategies for complete 'rejuvenation' of the RPMs' phagocytic activity, which may further alleviate the excessive splenic hemolysis, formation of iron-rich aggregates, and hence fully restore plasma iron availability.

Erythrocyte removal by iron recycling macrophages is considered an essentially constitutive process. Recent advances showed that the intensity of EP can be enhanced by proinflammatory conditions and pathogen components (Bennett et al., 2019; Bian et al., 2016; Delaby et al., 2012). The PIEZO1 mechanoreceptor was identified as a positive regulator of RBCs capture and was shown to control calcium levels and actin remodeling in iron-recycling macrophages (Ma et al., 2021). However, it was unknown if the RBCs uptake and lysis rates are regulated by iron availability per se. Our study identified three factors that affect the intensity of EP, the iron content, the activity of HO-1, and ER stress. Among them, labile and total iron accumulation in RPMs, independently of ROS generation, emerged as a major driver of EP suppression during aging. The underlying mechanisms for the presence of excessive iron in aged RPMs likely include reduced FPN protein levels and deficient $\mathrm{H}$ ferritin that detoxifies redoxactive ferrous iron (Mleczko-Sanecka and Silvestri, 2021). It is also plausible that, like neurons, aged RPMs may also show low capacity for heme synthesis (Atamna et al., 2002), which may lead to defective iron utilization in the mitochondria and increased cytoplasmic iron burden.

Another medically relevant condition that is hallmarked by hepcidin-dependent and/or independent iron retention in RPMs is inflammation (Guida et al., 2015; Kim et al., 2014). It remains to be investigated whether, under such circumstances, iron accumulation contributes to the EP rate. Given that the net outcome in young mice is EP stimulation (Bennett et al., 2019; Bian et al., 2016; Delaby et al., 2012), it is plausible that the suppressive effect of iron is either overridden by inflammatory signals or sole iron retention does not modulate EP. Our study suggests that aged mice characterized by defective RPMs may not potentiate EP rate in response to inflammation. Since this phenomenon was proposed to activate stress erythropoiesis (Bennett et al., 2019), age progression may impair this adaptive response and hence impede the recovery from inflammation-triggered anemia. We also demonstrated that iron loading decreases the lysosomal activity of iRPMs and that lysosomal activity in iRPMs in vivo closely reflects their iron status. Excessive iron was shown to promote ROS-triggered lysosomal membrane permeabilization (Kurz et al., 2011) and to inhibit phagosome fusion with lysosomes (Kelley and Schorey, 2003). Our data assign physiological context to this knowledge, as RPMs constitutive rely on lysosomal activity to exert their functions. 
The longevity of RPMs (Hashimoto et al., 2013; Liu et al., 2019) puts pressure on the cell to handle the constant flux of iron and globin-derived amino acids. This may increase the probability of agingassociated disorders, including a build-up of proteotoxic elements in RPMs. Consistently, we found a clear signature for ER stress in aged RPMs. The mild suppressive effect of ER stress that we observed in iRPMs may be explained by the involvement of ER membranes in EP, at least in vitro, and more generally in phagocytosis (Delaby et al., 2012; Gagnon et al., 2002). Interestingly, it was also found that phagocytosis triggers ER stress in macrophages (Kim et al., 2018), providing another explanation of how ER stress may build up in constitutive phagocytes such as RPMs. The heme catabolizing enzyme HO-1 is well characterized for its cytoprotective, anti-oxidative, and anti-inflammatory function, mainly attributed to its products, $\mathrm{CO}$ and biliverdin (Gozzelino et al., 2010). More recently, HO-1 activity was proposed to prevent cellular senescence in endothelial cells, fibroblasts or macrophages, via decreasing ROS levels, improving mitochondria function, or protecting from DNA damage (Even et al., 2018; Hedblom et al., 2019; Luo et al., 2018; Suliman et al., 2017). Iron recycling RPMs are key cells where HO-1 exerts its enzymatic function (Vijayan et al., 2018) and complete HO-1 deletion in mice leads to RPMs death (Kovtunovych et al., 2010). Our observation that HO-1 levels decrease in these cells during aging is thus of high physiological significance. As aged RPMs show some hallmarks of senescence linked to HO-1 deficiency, such as defective mitochondria or excessive ROS, they do not exhibit proinflammatory gene expression signatures. Instead, our RNA seq data reveal rather an antiinflammatory transcriptional pattern, exemplified by the downregulation of genes encoding for MHC class II complexes and the induction of Il-10. Future research may address if such skewing of aged RPMs may contribute to immunosenescence that accompanies aging (Nikolich-Zugich, 2018). Interestingly, the expansion of iron-recycling KCs that we observed in aged mice may exert further immunosuppressive functions, as shown previously for the liver macrophages exposed to erythrolytic stress (Olonisakin et al., 2020; Pfefferle et al., 2020).

The observation that HO-1 inhibition suppresses EP may be underlain by the inhibitory effect of heme overload on general phagocytosis in macrophages (Martins et al., 2016). However, unlike standard BMDMs (data not shown), heme-supplemented iRPMs failed to modulate EP in response to exposure to excessive hemin, implying efficient heme catabolism via HO-1. We further provide evidence that another product of $\mathrm{HO}-1, \mathrm{CO}$, restores the EP capacity of cells subjected to HO-1 suppression, thus emerging as an inducer of RBCs uptake. These findings are in agreement with the previous work, reporting that $\mathrm{CO}$ administration protects $\mathrm{HO}-1$ knock-out mice from sepsis-induced lethality via stimulation of bacterial phagocytosis (Chung et al., 2008). Whether deficient CO levels in RPMs in vivo contribute to EP suppression requires further investigation. Nevertheless, in support of this possibility, our RNA seq data imply that enzymes involved in the pentose phosphate pathway, such Tkt, Taldo or $G 6 p d$, transcriptional targets of CO-mediated regulation, are downregulated in aged RPMs. 
bioRxiv preprint doi: https://doi.org/10.1101/2022.01.16.476518; this version posted January 19, 2022. The copyright holder for this preprint (which was not certified by peer review) is the author/funder, who has granted bioRxiv a license to display the preprint in perpetuity. It is made available under aCC-BY-ND 4.0 International license.

Collectively, our work demonstrates that age-triggered and iron-dependent functional defects of RPMs, specialized cells that supply iron to the organism, emerge during early aging and disrupt internal iron turnover.

\section{Materials and Methods}

\section{Mice}

Female C57BL/6J mice were used for all the experiments and were maintained in pathogen-free conditions at the Experimental Medicine Centre (Bialystok, Poland). Starting with the age of 4 weeks mice were fed a diet with a standard iron content (200 mg/kg, SAFE \#U8958v0177; for Young and Aged), as described before,(Kautz et al., 2008; Pagani et al., 2011) or reduced iron content [ $25 \mathrm{mg} / \mathrm{kg}$; SAFE \#U8958v0294; for Aged iron reduced (IR)]. Diets were from SAFE (Augy, France). Mice were analyzed at 8-10 weeks (Young) and 10-11 months (Aged and Aged IR) of age. For supplementation with N-Acetyl-L-cysteine (NAC), aging mice (Aged NAC) were supplied with NAC dissolved in drinking water $(2 \mathrm{~g} / \mathrm{L})$ from 8 weeks of age until 10-11 months of age. Mice were delivered to the local facility at the IIMCB and sacrificed after short acclimatization, or subjected to additional procedures, if applicable. All procedures were approved by the local ethical communities in Olsztyn and Warsaw (decisions: WAW2/015/2019; WAW2/026/2020; WAW2/149/2020).

\section{Preparation of single-cell suspension from mouse organs}

Bone marrow cells were harvested by flushing the femur and tibia using a $25 \mathrm{G}$ needle and sterile HBSS medium (Gibco, 14025092). Cells were centrifuged at $600 \mathrm{~g}$ for 10 minutes at $4^{\circ} \mathrm{C}$. The spleen was excised and mashed through a $70 \mu \mathrm{m}$ strainer (pluriSelect, 43-50070-51). For FACS and magnetic sorting, the spleen was additionally digested in HBSS medium containing $1 \mathrm{mg} / \mathrm{ml}$ Collagenase D (Roche, 11088882001) and $50 \mathrm{U} / \mathrm{ml}$ DNase I for 30 minutes at $37^{\circ} \mathrm{C}$. After that cells were washed with cold HBSS and centrifuged at $600 \mathrm{~g}$ for 10 minutes at $4{ }^{\circ} \mathrm{C}$. The liver was extracted and perfused using Liver Perfusion Medium (Gibco, 17701038). Next, the organ was minced and digested in Liver Digest Medium (Gibco, 17703034) for 30 minutes at $37^{\circ} \mathrm{C}$. After that liver was pressed through a $70 \mu \mathrm{m}$ strainer in the presence of HBSS. Cells were centrifuged at $50 \mathrm{~g}$ for 3 minutes and the pellet was discarded (hepatocytes). The supernatant was centrifuged at $700 \mathrm{~g}$ for 15 minutes at $4^{\circ} \mathrm{C}$. Pellet was resuspended in $5 \mathrm{~mL}$ of PBS containing 0,5\% BSA and $5 \mathrm{~mL}$ of 50\% Percoll (Cytiva, 17-0891-01) diluted in PBS. The suspension was centrifuged at $700 \mathrm{~g}$ for 30 minutes at $20^{\circ} \mathrm{C}$. Blood was collected to a heparin-coated tube via heart puncture. Cells were washed with HBSS medium and centrifuged at 400g for 10 minutes at $4^{\circ} \mathrm{C}$. For peritoneal cell isolation, peritoneal cavities were washed with HBSS medium, and the peritoneal fluid was aspirated and filtered through $70 \mu \mathrm{m}$ strainer, and cells were centrifuged at $600 \mathrm{~g}$ for $5 \min$ at $4^{\circ} \mathrm{C}$.

RBCs present in a single-cell suspension were lysed using 1X RBC Lysis buffer (BioLegend, 420302) for 3 minutes at $4{ }^{\circ} \mathrm{C}$. This step was omitted for analyses of erythroid cells and RBCs. Next, cells were 
washed with HBSS and centrifuged at $600 \mathrm{~g}$ for 10 minutes at $4^{\circ} \mathrm{C}$. Pellet was prepared for further functional assays and labeling with antibodies.

\section{Generation of iRPMs and treatments}

Sterile harvested mononuclear cells obtained from mouse femurs and tibias were cultured at $37^{\circ} \mathrm{C}$ in $5 \%$ $\mathrm{CO}_{2}$ at $0.5 \times 10^{6} / 1 \mathrm{~mL}$ concentration in RPMI-1640 (Sigma-Aldrich, R2405) supplemented with 10\% FBS (Cytiva, SV30160.03), 1X Penicillin-Streptomycin (Gibco, 15140122), and $20 \mathrm{ng} / \mathrm{mL}$ macrophage colony-stimulating factor (BioLegend, 576406). On the $4^{\text {th }}$ and $6^{\text {th }}$ day medium was changed to fresh, supplemented with $20 \mu \mathrm{M}$ of hemin (Sigma-Aldrich, 51280) and $10 \mathrm{ng} / \mathrm{mL}$ of IL-33 (BioLegend, 580506). Assays were performed on the $8^{\text {th }}$ day.

For treatments, ferric ammonium citrate (FAC, Sigma-Aldrich, F5879), CORM-A1 (Sigma-Aldrich, SML0315), and deferoxamine (Sigma-Aldrich, D9533) were diluted in sterile ddH2O. Zinc (II) Protoporphyrin IX (Sigma-Aldrich, 691550), paraquat dichloride hydrate (Supelco, 36541), and tunicamycin (Sigma-Aldrich, T7765) were diluted in anhydrous DMSO. Hemin (Sigma-Aldrich, 51280) solution was prepared with $0.15 \mathrm{M} \mathrm{NaCl}$ containing $10 \% \mathrm{NH} 4 \mathrm{OH}$. All reagents after dilution were filtered through a $0,22 \mu \mathrm{m}$ filter and stored in $-20^{\circ} \mathrm{C}$ except ferric ammonium citrate, which was always freshly prepared. Concentrations and time of treatments are indicated in the descriptions of the figures.

\section{Flow cytometric analysis and cell sorting}

Cell suspensions of spleens and livers and iRPMs $\left(\sim 1 \times 10^{7}\right)$ were stained with LIVE/DEAD Fixable Aqua/Violet (Invitrogen, L34966/L34964) as per the manufacturer's instructions to identify dead cells. After extensive washing, the cells were incubated with Fc block in a dilution of 1:100 in FACS buffer for $10 \mathrm{~min}$ at $4{ }^{\circ} \mathrm{C}$. Cells were then stained with fluorophore-conjugated antibodies, dilution of 1:100 to 1:400, depending on the titration, in FACS buffer for $30 \mathrm{~min}$ at $4^{\circ} \mathrm{C}$. Cells were washed thoroughly with FACS buffer and subjected to flow cytometry analysis. For analysis of splenic RPM populations, the following surface antibodies were used: CD45 (Biolegend, 30-F11), CD45R/B220 (Biolegend, RA36B2), F4/80 (Biolegend, BM8), CD11b (Biolegend, M1/70) and TREML4 (Biolegend, 16E5). TER-119 (Biolegend) and CD71 (Biolegend, RI7217) were included for erythroid cell analysis. For analysis of liver Kupffer cell and iRPM populations, the following surface antibodies were used: CD45 (Biolegend, 30-F11), F4/80 (Biolegend, BM8) and CD11b (Biolegend, M1/70). Detection of FPN was performed with a non-commercial antibody that recognizes the extracellular loop of mouse FPN [rat monoclonal, Amgen, clone 1C7 (Sangkhae et al., 2019); directly conjugated with Alexa Fluor 488 Labeling Kit (Abcam, ab236553)]. For analysis of RBCs, the following surface antibodies were used: CD45 (Biolegend, 30-F11), TER-119 (Biolegend) and CD71 (Biolegend, RI7217). For analysis of peritoneal macrophages, the following surface antibodies were used: CD45 (Biolegend, 30-F11), F4/80 (Biolegend, BM8), MHCII (Biolegend, M5/114.15.2) and CD11b (Biolegend, M1/70). Events were 
either acquired on Aria II (BD Biosciences) or CytoFLEX (Beckman Coulter) and were analyzed with FlowJo or CytExpert, respectively.

For RNA sequencing (RNA-seq) and ATP levels quantification, RPMs were sorted into Trizol-LS (Invitrogen, 10296010) or assay buffer, respectively, using an Aria II cell sorter (BD Biosciences) with an $85 \mu \mathrm{m}$ nozzle.

\section{Functional Assays and detection of intracellular ferrous iron}

Intracellular ROS (APC channel) levels were determined by using CellROX Deep Red Reagent (Invitrogen, C10422) fluorescence according to the manufacturer's instructions. Lipid peroxidation (FITC vs PE channels) was determined with the Lipid Peroxidation Assay Kit (Abcam, ab243377) according to the manufacturer's instructions. Mitochondria-associated ROS (PE channel) levels were measured with MitoSOX Red (Invitrogen, M36008) at $2.5 \mu \mathrm{M}$ for $30 \mathrm{~min}$ at $37^{\circ} \mathrm{C}$. Lysosomal activity (FITC channel) was determined by using Lysosomal Intracellular Activity Assay Kit (Biovision, K448) according to the manufacturer's instructions. Proteasomal activity (FITC channel) was determined using Me4BodipyFL-Ahx3Leu3VS fluorescent proteasome activity probe (R\&D Systems, I-190) at 2 $\mu \mathrm{M}$ for 1 hour at $37^{\circ} \mathrm{C}$. Mitochondria activity (membrane potential, PE channel) was measured using a tetramethylrhodamine ethyl ester (TMRE) fluorescent probe (Sigma-Aldrich, 87917) at $400 \mathrm{nM}$ for 30 min at $37^{\circ} \mathrm{C}$. Mitochondrial mass (FITC/PE channel) was measured by fluorescence levels upon staining with MitoTracker Green (Invitrogen, M7514) at $100 \mathrm{nM}$ for $30 \mathrm{~min}$ at $37^{\circ} \mathrm{C}$.

The content of intracellular ferrous iron (PE channel) $\left(\mathrm{Fe}^{2+}\right)$ was measured using FerroOrange (DojinD) via flow cytometric analysis. Briefly, surface-stained cells were incubated with $1 \mu \mathrm{M}$ FerroOrange in HBSS for $30 \mathrm{~min}$ at $37^{\circ} \mathrm{C}$, and analyzed directly via flow cytometry without further washing, as described above.

For intracellular staining, surface-stained cells were first fixed with 4\% PFA and permeabilized with $0.5 \%$ Triton-X in PBS. The cells were then stained with respective primary antibodies for $1 \mathrm{~h}$ at $4^{\circ} \mathrm{C}$ followed by 30 min staining with Alexa Fluor 488 or Alexa Fluor 647 conjugated anti-Rabbit IgG (1:1000 Thermo Fisher, A-21206). The following rabbit anti-mouse intracellular primary antibodies were used: Ferritin Heavy Chain (FTH1, Cell Signaling Technology, 3998), Ferritin Light Chain (FTL, Abcam, ab69090) and HO-1 polyclonal antibody (ENZO, ADI-SPA-896).

The cells were subsequently stained with cell surface markers and the geometric mean fluorescence intensities (MFI) corresponding to the probes/target protein levels were determined by flow cytometry acquired on Aria II (BD Biosciences) or CytoFLEX (Beckman Coulter) and were analyzed with FlowJo or CytExpert, respectively. For the probes that have emission in PE, TREML4 was excluded, and RPMs were gated as F4/80-high CD11b-dim. For quantifications, MFI of the adequate fluorescence minus one (FMO) controls were subtracted from samples MFI, and data were further normalized. 


\section{ATP levels}

Cellular ATP levels in FACS-sorted RPMs (10000 cells/sample) were determined using ATP Fluorometric Assay Kit (Sigma, MAK190), as per the manufacturer's instructions.

\section{Magnetic sorting of RPMs and isolation of extracellular iron-containing aggregates}

$60 \times 10^{6}$ of mouse splenocytes were incubated for 15 minutes at $4^{\circ} \mathrm{C}$ in PBS containing $5 \%$ Normal Rat Serum (Thermo Scientific, 10710C) and anti-CD16/32 (BioLegend, 101320) antibody in 5mL round bottom tube. Afterward, cells were labeled with anti-F4/80 (APC, BioLegend, 123116) and anti-B220 (Biotin, BioLegend, 103204) for 20 minutes in $4^{\circ} \mathrm{C}$ in dark. Next, cells were washed with cold PBS containing $2 \mathrm{mM}$ EDTA, $0.5 \%$ BSA (hereafter referred to as "sorting buffer"), and centrifuged at $600 \mathrm{~g}$ for 10 minutes. Pellet was resuspended in $350 \mu \mathrm{L}$ of sorting buffer containing $35 \mu \mathrm{L}$ of MojoSort Streptavidin Nanobeads (BioLegend, 480016) and kept in cold and dark for 15 minutes. After incubation, an additional $350 \mu \mathrm{L}$ was added to cells, and the tube was placed on EasyEights EasySep Magnet (STEMCELL, 18103) for 7 minutes. After that supernatant was transferred to a fresh $5 \mathrm{~mL}$ tube and centrifuged at $600 \mathrm{~g}$ for 10 minutes. Pellet was resuspended in $100 \mu \mathrm{L}$ of sorting buffer and $10 \mu \mathrm{L}$ of MojoSort Mouse anti-APC Nanobeads (BioLegend, 480072) was added. The suspension was gently pipetted and incubated for 15 minutes at $4^{\circ} \mathrm{C}$ in dark. Afterward, the tube was placed on a magnet for 7 minutes. Next, the supernatant was saved for analysis, and beads with attached F4/80+/B220- cells were washed with sorting buffer and counted under a light microscope with a Neubauer chamber. Cells were pelleted and frozen in liquid nitrogen for further analysis.

For isolation of extracellular iron-containing aggregates, splenocytes were resuspended in HBSS and then carefully layered over Lymphosep (3:1) in a FACS tube, creating a sharp spleen cell suspensionLymphosep interphase. Leukocytes were sorted out from the supernatant after density centrifugation at $400 \mathrm{~g}$ at $20^{\circ} \mathrm{C}$ for $25 \mathrm{~min}$. The pellet comprising mostly RBCs, granulocytes, and extracellular ironcontaining aggregates was then washed again with HBSS to remove Lymphosep. The cell pellet was resuspended in sorting buffer and then passed through a magnetized LS separation column (Miltenyi Biotec). The iron-containing superparamagnetic cells/aggregates were eluted from the demagnetized column, washed, and re-suspended in sorting buffer. To achieve a pure yield of extracellular ironcontaining aggregates and remove any trace contaminations from superparamagnetic RPMs or B cells (highly abundant in the spleen), cells expressing F4/80 and B220 were sorted out using MojoSort magnetic cell separation system as previously described. The remaining material comprising of mostly aggregates was washed thoroughly and either pelleted and frozen in liquid nitrogen for further analysis (mass spectrometry and iron/heme measurements) or stained with fluorophore-conjugated antibodies, including CD45 (Biolegend, 30-F11), TER-119 (Biolegend), CD71 (Biolegend, RI7217), F4/80 (Biolegend, BM8) and CD11b (Biolegend, M1/70). Cells were washed with FACS buffer, and the ironcontaining aggregates were analyzed via flow cytometry. 
bioRxiv preprint doi: https://doi.org/10.1101/2022.01.16.476518; this version posted January 19, 2022. The copyright holder for this preprint (which was not certified by peer review) is the author/funder, who has granted bioRxiv a license to display the preprint in perpetuity. It is made available under aCC-BY-ND 4.0 International license.

\section{Measurement of cellular iron levels}

Determination of cellular total iron levels in magnetically-sorted RPMs and total spleens was carried out using the Iron assay Kit (Sigma-Aldrich, MAK025) according to the manufacturer's instructions, and as shown previously(Folgueras et al., 2018) Iron concentrations $(\mathrm{ng} / \mu \mathrm{L})$ were calculated from the standard curve and normalized to the number of cells for each sample/spleen weight.

\section{RBCs in vivo lifespan}

EZ-Link Sulfo-NHS Biotin (Thermo Scientific, 21217) was dissolved in sterile PBS to a final concentration of $1 \mathrm{mg}$ per $100 \mu \mathrm{L}$ and filtered through a $0,1 \mu \mathrm{m}$ filter (Millipore, SLVV033RS). A day before the first blood collection, $100 \mu \mathrm{L}$ of the sterile solution was injected intravenously into mice. On days $0,4,11,18$, and 25 approximately $10 \mu \mathrm{L}$ of whole blood was collected from the tail vein with heparinized capillary to tube containing HBSS. RBCs were centrifuged at $400 \mathrm{~g}$ for 5 minutes at $4{ }^{\circ} \mathrm{C}$. Each sample was resuspended in $250 \mu \mathrm{L}$ of HBSS containing $5 \%$ normal rat serum (Thermo Scientific). Then $2 \mu \mathrm{L}$ of fluorescently labeled anti-TER-119 and streptavidin was added to the suspension. Fluorescent streptavidin was omitted for FMO samples in each group. After incubation at $4^{\circ} \mathrm{C}$ for 30 minutes, samples were centrifuged and resuspended with HBSS. The percentage of biotinylated erythrocytes was determined by flow cytometry.

\section{Preparation of stressed erythrocytes for erythrophagocytosis assays}

Preparation and staining of stressed RBCs (sRBCs) were performed as described before (Theurl et al., 2016), with some modifications. Preparation of RBCs: Mice were sacrificed and whole blood was aseptically collected via cardiac puncture to CPDA-1 solution (Sigma-Aldrich, C4431). The final concentration of CPDA-1 was $10 \%$. Whole blood obtained from mice was pooled and then centrifuged at $400 \mathrm{~g}$ for 15 minutes at $4{ }^{\circ} \mathrm{C}$. Plasma was collected and filtered through a $0.1 \mu \mathrm{m}$ filter and stored at $4^{\circ} \mathrm{C}$. RBCs were resuspended in HBSS and leukoreduced using Lymphosep (Biowest, L0560-500). Cells were washed with HBSS and then heated for $30 \mathrm{~min}$ at $48^{\circ} \mathrm{C}$ while continuously shaking, generating sRBC. Staining of sRBCs: $1 \times 10^{10} \mathrm{RBC}$ were resuspended in $1 \mathrm{ml}$ diluent $\mathrm{C}$, mixed with 1 $\mathrm{ml}$ diluent $\mathrm{C}$ containing $4 \mu \mathrm{M}$ PKH-67 (Sigma-Aldrich, MIDI67-1KT) and incubated in dark for 5 minutes in $37^{\circ} \mathrm{C}$, the reaction was stopped by adding $10 \mathrm{~mL}$ HBSS containing $2 \%$ FCS and $0.5 \%$ BSA. Staining was followed by two washing steps with HBSS. For in vitro and ex vivo erythrophagocytosis assay cells were resuspended in RPMI-1640 and counted.

For in vivo approach, RBCs were resuspended to $50 \%$ hematocrit in previously collected and filtered plasma.

\section{In vitro erythrophagocytosis}

Stained and counted sRBCs were added to iRPMs on 12 -well plates in 10 fold excess for $1.5 \mathrm{~h} \mathrm{in} 37^{\circ} \mathrm{C}$, $5 \% \mathrm{CO}_{2}$ on the $8^{\text {th }}$ day after seeding. After that cells were extensively washed with cold PBS to discard 
not engulfed sRBCs. Next, cells were detached with Accutase (BioLegend, 423201), transferred to a round bottom tube, washed with HBSS, and centrifuged at $600 \mathrm{~g}$ for 5 minutes. Cells were labeled with antibodies and analyzed by flow cytometry.

\section{In vivo erythrophagocytosis}

Mice were injected into the tail vein with $100 \mu \mathrm{L}$ of RBCs resuspended in plasma to $50 \%$ hematocrit. Mice were maintained for $1.5 \mathrm{~h}$ in cages with constant access to water and food. After that time animals were sacrificed for organ isolation.

\section{Ex vivo phagocytosis and erythrophagocytosis}

$10 \times 10^{6}$ splenocytes were resuspended in a $5 \mathrm{~mL}$ round bottom tube in $200 \mu \mathrm{L}$ of warm complete RPMI1640. Fluorescent sRBCs or fluorescent Zymosan A particles (Invitrogen, Z23373) were added to cells at ratio 10:1 (sRBCs/Zymosan : Cells) for $1.5 \mathrm{~h}$ at $37^{\circ} \mathrm{C}, 5 \% \mathrm{CO}_{2}$. Afterward, cells were centrifuged at $600 \mathrm{~g}$ for 5 minutes. Excess of sRBCs was lysed using $1 \mathrm{X}$ RBCs lysis buffer, cells were washed with HBSS and centrifuged. Next, cells were labeled with fluorescent antibodies and analyzed by flow cytometry.

\section{Heme content analysis}

The whole spleen was weighted, quickly dissected and gently mashed through a $100 \mu \mathrm{m}$ strainer in the presence of $3 \mathrm{~mL}$ HBSS. After that suspension was centrifuged at $400 \mathrm{~g}$ for 10 minutes at $4{ }^{\circ} \mathrm{C}$. A splenocyte pellet was used for different purposes and $1 \mathrm{~mL}$ of heme-containing supernatant was transferred to a $1,5 \mathrm{~mL}$ tube and centrifuged at $1000 \mathrm{~g}$ for 10 minutes at $4{ }^{\circ} \mathrm{C}$.

Splenic aggregates were isolated as previously described and were suspended in $\mathrm{dd}_{2} \mathrm{O}$ water. $\mathrm{Heme}$ concentration was measured using Heme Assay Kit (Sigma-Aldrich, MAK316) according to manufacturer instructions. Absorbance was measured at $400 \mathrm{~nm}$. The amount of heme was calculated against Heme Calibrator and normalized to the initial weight of fresh spleens.

\section{Transferrin saturation and tissue iron measurements}

Serum iron and unsaturated iron-binding capacity were measured with SFBC (Biolabo, 80008) and UIBC (Biolabo, 97408) kits according to manufacturer protocols. Transferrin saturation was calculated using the formula SFBC/(SFBC+UIBC)x100. For measurement of tissue non-heme iron content, the bathophenanthroline method was applied and calculations were made against dry weight tissue, as described previously (Torrance and Bothwell, 1968). 


\section{Erythropoietin (EPO) measurement with ELISA}

The plasma levels of erythropoietin were measured by Mouse Erythropoietin/EPO Quantikine ELISA Kit (R\&D Systems, MEP00B) according to the manufacturers instructions. The optical density was measured on microplate reader at a wavelength of $450 \mathrm{~nm}$ with wavelength correction set to $570 \mathrm{~nm}$.

\section{RNA isolation}

RNA from sorted cells was isolated from TRIzol LS Reagent (Invitrogen, 10296028) using Direct-zol RNA Microprep Kit (Zymo Research, R2062) according to the manufacturer's instructions. RNA from tissues was isolated from TRIzol Reagent (Invitrogen, 15596018) following the guidelines of the manufacturer protocol.

\section{Reverse transcription and qRT-PCR}

cDNA was synthesized with RevertAid H Minus Reverse Transcriptase (Thermo Scientific, EP0452) according to manufacturer guidelines. Real-time PCR was performed by using SG qPCR Master Mix (EURx, E0401) and HAMP gene primers (Forward 5'-ATACCAATGCAGAAGAGAAGG-3', Reverse 5'-AACAGATACCACACTGGGAA-3') as described in manufacturer protocol. qRT-PCR was run on LightCycler 96 System (Roche).

\section{Histological and histochemical analysis}

Following fixation in $10 \%$ formalin for $24 \mathrm{~h}$, spleens were stored in $70 \%$ ethanol before further preparation. The tissue was embedded in paraffin and $7-\mu \mathrm{m}$ cross-sections were cut with a microtome (Reichert-Jung, Germany). The sections were stained with hematoxylin and eosin. Slides were examined by light microscopy (Olympus, type $\mathrm{CH} 2$ ). Non-heme iron staining of spleen samples was analyzed using Accustain Iron Deposition Kit (Sigma). Sections were prepared as described above. After mounting on glass slides, sections were deparaffinized, incubated with a working solution containing Perls' Prussian Blue for $30 \mathrm{~min}$, counterstained with pararosaniline solution for $2 \mathrm{~min}$ and analyzed under standard light microscopy (Olympus $\mathrm{CH} 2$ ).

\section{Transcriptome analysis by RNA-seq}

To prepare libraries from FACS-sorted RPMs (at least 100000 cells/sample), we used the previously described Smart-seq2 protocol (Picelli et al., 2013), suitable for low-input total mRNA sequencing. The quality of RNA and material during the preparation of libraries was checked by Bioanalyzer. The samples were sequenced on NextSeq500 (Illumina) with 75 bp single-end reads, with 50 million reads/sample. RNAseq was performed at GeneCore at EMBL (Heidelberg, Germany). The quality of the reads was assessed with FastQC software [https://www.bioinformatics.babraham.ac.uk/projects/fastqc/]. Reads were mapped to the Mus musculus genome assembly GRCm38(mm10) with HISAT2 software 
[http://daehwankimlab.github.io/hisat2/] on default parameters. Then, the mapped reads were counted into Ensembl annotation intervals using HTSeq-count software [https://www.ncbi.nlm.nih.gov/labs/pmc/articles/PMC4287950/]. Differentially expressed genes were estimated using DESeq2 software [https://www.ncbi.nlm.nih.gov/labs/pmc/articles/PMC4302049/] with default parameters. Genes with p-adjusted $<0.05$ were regarded as differentially expressed and included in further analysis. Functional analysis was conducted using ClusterProfiler [https://doi.org/10.1016/j.xinn.2021.100141].

\section{Statistical analysis}

Statistical analysis was performed with GraphPad Prism (GraphPad software, Version 9). Data are represented as mean \pm SEM, unless otherwise specified. For all experiments, $\alpha=0.05$. When two groups were compared two-tailed unpaired Welch's t-test was applied, whereas for multiple comparisons, the One-Way Analysis of Variance (ANOVA) test was performed. For ANOVA, Dunnett's Multiple Comparison test was used for experiments comparing multiple experimental groups to a single control, while post-hoc Tukey's test was used to compare multiple experimental groups. The number of samples per group or number of independent experiments are shown in the figures. Results were considered as significant for $\mathrm{p}<0.05, * *-\mathrm{p}(*-\mathrm{p}<0.05, * *-\mathrm{p}<0.01, * * *-\mathrm{p}<0.001, * * * *-\mathrm{p}<0.0001)$

\section{Author contribution}

Conceptualization: PKM, PS, WP, KMS; Formal analysis: PKM, PS, GZ, OK, MM, ML, RS, WP, KMS; Funding acquisition: MM, ML, WP, KMS, Investigation: PKM, PS, GZ, SH, ML, KMS; Methodology; PKM, PS, GZ, MC, OK, SH, ML, RS, KMS; Project administration: WP, KMS; Resources: WP, KMS; Supervision: WP, KMS; Validation: MM, ML, WP, KMS; Visualization: PKM, PS, GZ, OK, ML, KMS; Writing - original draft: PKM, PS, KMS; Writing - review \& editing: WP, KMS.

\section{Acknowledgments}

We thank the GeneCore team (EMBL, Heidelberg) for performing RNA sequencing. We thank Tara Arvedson (Amgen Inc., USA) for the anti-ferroportin antibody. Many thanks to Agnieszka Popielska and the staff of the Experimental Medicine Centre (Bialystok, Poland) for their technical support. WP and KMS acknowledge internal IIMCB funding for inter-lab projects. WP acknowledges funding from Norwegian Financial Mechanism 2014-2021 and operated by the Polish National Science Center under the project contract no UMO-2019/34/H/NZ3/00691 and European Molecular Biology Organization (EMBO Installation Grant No. 3916). KMS acknowledges funding from the National Science Centre Sonata Bis grant (UMO-2020/38/E/NZ4/00511). 
bioRxiv preprint doi: https://doi.org/10.1101/2022.01.16.476518; this version posted January $19,2022$. The copyright holder for this preprint (which was not certified by peer review) is the author/funder, who has granted bioRxiv a license to display the preprint in perpetuity. It is made available under aCC-BY-ND 4.0 International license.

\section{References}

Akilesh, H.M., Buechler, M.B., Duggan, J.M., Hahn, W.O., Matta, B., Sun, X., Gessay, G., Whalen, E., Mason, M., Presnell, S.R., et al. (2019). Chronic TLR7 and TLR9 signaling drives anemia via differentiation of specialized hemophagocytes. Science 363.

Altamura, S., Kessler, R., Grone, H.J., Gretz, N., Hentze, M.W., Galy, B., and Muckenthaler, M.U. (2014). Resistance of ferroportin to hepcidin binding causes exocrine pancreatic failure and fatal iron overload. Cell Metab 20, 359-367.

Arashiki, N., Kimata, N., Manno, S., Mohandas, N., and Takakuwa, Y. (2013). Membrane peroxidation and methemoglobin formation are both necessary for band 3 clustering: mechanistic insights into human erythrocyte senescence. Biochemistry 52, 5760-5769.

Arruda, L.F., Arruda, S.F., Campos, N.A., de Valencia, F.F., and Siqueira, E.M. (2013). Dietary iron concentration may influence aging process by altering oxidative stress in tissues of adult rats. PLoS One 8 , e61058.

Aschemeyer, S., Qiao, B., Stefanova, D., Valore, E.V., Sek, A.C., Ruwe, T.A., Vieth, K.R., Jung, G., Casu, C., Rivella, S., et al. (2018). Structure-function analysis of ferroportin defines the binding site and an alternative mechanism of action of hepcidin. Blood 131, 899-910.

Atamna, H., Killilea, D.W., Killilea, A.N., and Ames, B.N. (2002). Heme deficiency may be a factor in the mitochondrial and neuronal decay of aging. Proc Natl Acad Sci U S A 99, 14807-14812.

Bennett, L.F., Liao, C., Quickel, M.D., Yeoh, B.S., Vijay-Kumar, M., Hankey-Giblin, P., Prabhu, K.S., and Paulson, R.F. (2019). Inflammation induces stress erythropoiesis through heme-dependent activation of SPI-C. Sci Signal 12.

Berman, A.E., Chan, W.Y., Brennan, A.M., Reyes, R.C., Adler, B.L., Suh, S.W., Kauppinen, T.M., Edling, Y., and Swanson, R.A. (2011). N-acetylcysteine prevents loss of dopaminergic neurons in the EAAC1-/- mouse. Ann Neurol 69, 509-520.

Bian, Z., Shi, L., Guo, Y.L., Lv, Z., Tang, C., Niu, S., Tremblay, A., Venkataramani, M., Culpepper, C., Li, L., et al. (2016). Cd47-Sirpalpha interaction and IL-10 constrain inflammation-induced macrophage phagocytosis of healthy self-cells. Proc Natl Acad Sci U S A 113, E5434-5443.

Bratosin, D., Mazurier, J., Tissier, J.P., Estaquier, J., Huart, J.J., Ameisen, J.C., Aminoff, D., and Montreuil, J. (1998). Cellular and molecular mechanisms of senescent erythrocyte phagocytosis by macrophages. A review. Biochimie 80, 173-195.

Chung, S.W., Liu, X., Macias, A.A., Baron, R.M., and Perrella, M.A. (2008). Heme oxygenase-1derived carbon monoxide enhances the host defense response to microbial sepsis in mice. J Clin Invest $118,239-247$.

Cook, C.I., and Yu, B.P. (1998). Iron accumulation in aging: modulation by dietary restriction. Mech Ageing Dev 102, 1-13.

Cronin, S.J.F., Woolf, C.J., Weiss, G., and Penninger, J.M. (2019). The Role of Iron Regulation in Immunometabolism and Immune-Related Disease. Front Mol Biosci 6, 116.

Delaby, C., Rondeau, C., Pouzet, C., Willemetz, A., Pilard, N., Desjardins, M., and Canonne-Hergaux, F. (2012). Subcellular localization of iron and heme metabolism related proteins at early stages of erythrophagocytosis. PLoS One 7, e42199.

Even, B., Fayad-Kobeissi, S., Gagliolo, J.M., Motterlini, R., Boczkowski, J., Foresti, R., and Dagouassat, M. (2018). Heme oxygenase-1 induction attenuates senescence in chronic obstructive pulmonary disease lung fibroblasts by protecting against mitochondria dysfunction. Aging Cell 17, e12837. 
bioRxiv preprint doi: https://doi.org/10.1101/2022.01.16.476518; this version posted January $19,2022$. The copyright holder for this preprint (which was not certified by peer review) is the author/funder, who has granted bioRxiv a license to display the preprint in perpetuity. It is made available under aCC-BY-ND 4.0 International license.

Folgueras, A.R., Freitas-Rodriguez, S., Ramsay, A.J., Garabaya, C., Rodriguez, F., Velasco, G., and Lopez-Otin, C. (2018). Matriptase-2 deficiency protects from obesity by modulating iron homeostasis. Nat Commun 9, 1350.

Fox, J.B., S.; Davisson, M.; Newcomer, C.; Quimby, F.; Smith, A. (editors) (2006). The Mouse in Biomedical Research. Elsevier, AP.

Franken, L., Klein, M., Spasova, M., Elsukova, A., Wiedwald, U., Welz, M., Knolle, P., Farle, M., Limmer, A., and Kurts, C. (2015). Splenic red pulp macrophages are intrinsically superparamagnetic and contaminate magnetic cell isolates. Sci Rep 5, 12940.

Gagnon, E., Duclos, S., Rondeau, C., Chevet, E., Cameron, P.H., Steele-Mortimer, O., Paiement, J., Bergeron, J.J., and Desjardins, M. (2002). Endoplasmic reticulum-mediated phagocytosis is a mechanism of entry into macrophages. Cell 110, 119-131.

Ganz, T. (2012). Macrophages and systemic iron homeostasis. J Innate Immun 4, 446-453.

Girelli, D., Marchi, G., and Camaschella, C. (2018). Anemia in the Elderly. Hemasphere 2, e40.

Gottlieb, Y., Topaz, O., Cohen, L.A., Yakov, L.D., Haber, T., Morgenstern, A., Weiss, A., Chait Berman, K., Fibach, E., and Meyron-Holtz, E.G. (2012). Physiologically aged red blood cells undergo erythrophagocytosis in vivo but not in vitro. Haematologica 97, 994-1002.

Gozzelino, R., Jeney, V., and Soares, M.P. (2010). Mechanisms of cell protection by heme oxygenase1. Annu Rev Pharmacol Toxicol 50, 323-354.

Guida, C., Altamura, S., Klein, F.A., Galy, B., Boutros, M., Ulmer, A.J., Hentze, M.W., and Muckenthaler, M.U. (2015). A novel inflammatory pathway mediating rapid hepcidin-independent hypoferremia. Blood 125, 2265-2275.

Haldar, M., Kohyama, M., So, A.Y., Kc, W., Wu, X., Briseno, C.G., Satpathy, A.T., Kretzer, N.M., Arase, H., Rajasekaran, N.S., et al. (2014). Heme-mediated SPI-C induction promotes monocyte differentiation into iron-recycling macrophages. Cell 156, 1223-1234.

Hamza, I., and Dailey, H.A. (2012). One ring to rule them all: trafficking of heme and heme synthesis intermediates in the metazoans. Biochim Biophys Acta 1823, 1617-1632.

Hashimoto, D., Chow, A., Noizat, C., Teo, P., Beasley, M.B., Leboeuf, M., Becker, C.D., See, P., Price, J., Lucas, D., et al. (2013). Tissue-resident macrophages self-maintain locally throughout adult life with minimal contribution from circulating monocytes. Immunity 38, 792-804.

Hedblom, A., Hejazi, S.M., Canesin, G., Choudhury, R., Hanafy, K.A., Csizmadia, E., Persson, J.L., and Wegiel, B. (2019). Heme detoxification by heme oxygenase-1 reinstates proliferative and immune balances upon genotoxic tissue injury. Cell Death Dis 10, 72 .

Higgins, J.M. (2015). Red blood cell population dynamics. Clin Lab Med 35, 43-57.

Kautz, L., Meynard, D., Monnier, A., Darnaud, V., Bouvet, R., Wang, R.H., Deng, C., Vaulont, S., Mosser, J., Coppin, H., et al. (2008). Iron regulates phosphorylation of Smad1/5/8 and gene expression of Bmp6, Smad7, Id1, and Atoh8 in the mouse liver. Blood 112, 1503-1509.

Kelley, V.A., and Schorey, J.S. (2003). Mycobacterium's arrest of phagosome maturation in macrophages requires Rab5 activity and accessibility to iron. Mol Biol Cell 14, 3366-3377.

Kim, A., Fung, E., Parikh, S.G., Valore, E.V., Gabayan, V., Nemeth, E., and Ganz, T. (2014). A mouse model of anemia of inflammation: complex pathogenesis with partial dependence on hepcidin. Blood $123,1129-1136$.

Kim, S.H., Cho, S.N., Lim, Y.J., Choi, J.A., Lee, J., Go, D., and Song, C.H. (2018). Phagocytosis influences the intracellular survival of Mycobacterium smegmatis via the endoplasmic reticulum stress response. Cell Biosci 8, 52. 
bioRxiv preprint doi: https://doi.org/10.1101/2022.01.16.476518; this version posted January 19,2022 . The copyright holder for this preprint (which was not certified by peer review) is the author/funder, who has granted bioRxiv a license to display the preprint in perpetuity. It is made available under aCC-BY-ND 4.0 International license.

Klei, T.R., Meinderts, S.M., van den Berg, T.K., and van Bruggen, R. (2017). From the Cradle to the Grave: The Role of Macrophages in Erythropoiesis and Erythrophagocytosis. Front Immunol 8, 73.

Klei, T.R.L., Dalimot, J., Nota, B., Veldthuis, M., Mul, F.P.J., Rademakers, T., Hoogenboezem, M., Nagelkerke, S.Q., van, I.W.F.J., Oole, E., et al. (2020). Hemolysis in the spleen drives erythrocyte turnover. Blood 136, 1579-1589.

Kohyama, M., Ise, W., Edelson, B.T., Wilker, P.R., Hildner, K., Mejia, C., Frazier, W.A., Murphy, T.L., and Murphy, K.M. (2009). Role for Spi-C in the development of red pulp macrophages and splenic iron homeostasis. Nature 457, 318-321.

Kovtunovych, G., Eckhaus, M.A., Ghosh, M.C., Ollivierre-Wilson, H., and Rouault, T.A. (2010). Dysfunction of the heme recycling system in heme oxygenase 1-deficient mice: effects on macrophage viability and tissue iron distribution. Blood 116, 6054-6062.

Kurz, T., Eaton, J.W., and Brunk, U.T. (2011). The role of lysosomes in iron metabolism and recycling. Int J Biochem Cell Biol 43, 1686-1697.

Liu, Z., Gu, Y., Chakarov, S., Bleriot, C., Kwok, I., Chen, X., Shin, A., Huang, W., Dress, R.J., Dutertre, C.A., et al. (2019). Fate Mapping via Ms4a3-Expression History Traces Monocyte-Derived Cells. Cell $178,1509-1525$ e1519.

Lu, Y., Basatemur, G., Scott, I.C., Chiarugi, D., Clement, M., Harrison, J., Jugdaohsingh, R., Yu, X., Newland, S.A., Jolin, H.E., et al. (2020). Interleukin-33 Signaling Controls the Development of IronRecycling Macrophages. Immunity 52, $782-793$ e 785.

Luo, W., Wang, Y., Yang, H., Dai, C., Hong, H., Li, J., Liu, Z., Guo, Z., Chen, X., He, P., et al. (2018). Heme oxygenase-1 ameliorates oxidative stress-induced endothelial senescence via regulating endothelial nitric oxide synthase activation and coupling. Aging (Albany NY) 10, 1722-1744.

Lutz, H.U. (2012). Naturally Occurring Antibodies (NAbs). Advances in experimental medicine and biology 750, 0065-2598.

Ma, S., Dubin, A.E., Zhang, Y., Mousavi, S.A.R., Wang, Y., Coombs, A.M., Loud, M., Andolfo, I., and Patapoutian, A. (2021). A role of PIEZO1 in iron metabolism in mice and humans. Cell 184, 969-982 e913.

Ma, Y., Gao, M., and Liu, D. (2016). N-acetylcysteine Protects Mice from High Fat Diet-induced Metabolic Disorders. Pharm Res 33, 2033-2042.

Martins, R., Maier, J., Gorki, A.D., Huber, K.V., Sharif, O., Starkl, P., Saluzzo, S., Quattrone, F., Gawish, R., Lakovits, K., et al. (2016). Heme drives hemolysis-induced susceptibility to infection via disruption of phagocyte functions. Nat Immunol 17, 1361-1372.

Mebius, R.E., and Kraal, G. (2005). Structure and function of the spleen. Nature reviews Immunology $5,606-616$.

Mleczko-Sanecka, K., and Silvestri, L. (2021). Cell-type-specific insights into iron regulatory processes. Am J Hematol 96, 110-127.

Muckenthaler, M.U., Rivella, S., Hentze, M.W., and Galy, B. (2017). A Red Carpet for Iron Metabolism. Cell 168, 344-361.

Nemeth, E., Tuttle, M.S., Powelson, J., Vaughn, M.B., Donovan, A., Ward, D.M., Ganz, T., and Kaplan, J. (2004). Hepcidin regulates cellular iron efflux by binding to ferroportin and inducing its internalization. Science 306, 2090-2093.

Nikolich-Zugich, J. (2018). The twilight of immunity: emerging concepts in aging of the immune system. Nat Immunol 19, 10-19. 
bioRxiv preprint doi: https://doi.org/10.1101/2022.01.16.476518; this version posted January $19,2022$. The copyright holder for this preprint (which was not certified by peer review) is the author/funder, who has granted bioRxiv a license to display the preprint in perpetuity. It is made available under aCC-BY-ND 4.0 International license.

Okreglicka, K., Iten, I., Pohlmeier, L., Onder, L., Feng, Q., Kurrer, M., Ludewig, B., Nielsen, P., Schneider, C., and Kopf, M. (2021). PPARgamma is essential for the development of bone marrow erythroblastic island macrophages and splenic red pulp macrophages. J Exp Med 218.

Olonisakin, T.F., Suber, T.L., Gonzalez-Ferrer, S., Xiong, Z., Penaloza, H.F., van der Geest, R., Xiong, Y., Osei-Hwedieh, D.O., Tejero, J., Rosengart, M.R., et al. (2020). Stressed erythrophagocytosis induces immunosuppression during sepsis through heme-mediated STAT1 dysregulation. J Clin Invest.

Pagani, A., Nai, A., Corna, G., Bosurgi, L., Rovere-Querini, P., Camaschella, C., and Silvestri, L. (2011). Low hepcidin accounts for the proinflammatory status associated with iron deficiency. Blood $118,736-746$.

Pek, R.H., Yuan, X., Rietzschel, N., Zhang, J., Jackson, L., Nishibori, E., Ribeiro, A., Simmons, W., Jagadeesh, J., Sugimoto, H., et al. (2019). Hemozoin produced by mammals confers heme tolerance. Elife 8 .

Peters, L.L., Tsaih, S.W., and Yuan, R. (2008). Modeling Anemia of Aging in Inbred Mouse Strains. Blood 112, 1181-1182.

Pfefferle, M., Ingoglia, G., Schaer, C.A., Yalamanoglu, A., Buzzi, R., Dubach, I.L., Tan, G., LopezCano, E.Y., Schulthess, N., Hansen, K., et al. (2020). Hemolysis transforms liver macrophages into antiinflammatory erythrophagocytes. J Clin Invest 130, 5576-5590.

Picelli, S., Bjorklund, A.K., Faridani, O.R., Sagasser, S., Winberg, G., and Sandberg, R. (2013). Smartseq2 for sensitive full-length transcriptome profiling in single cells. Nat Methods 10, 1096-1098.

Qi, L., Tsai, B., and Arvan, P. (2017). New Insights into the Physiological Role of Endoplasmic Reticulum-Associated Degradation. Trends Cell Biol 27, 430-440.

Sangkhae, V., Fisher, A.L., Wong, S., Koenig, M.D., Tussing-Humphreys, L., Chu, A., Lelic, M., Ganz, T., and Nemeth, E. (2019). Effects of maternal iron status on placental and fetal iron homeostasis. J Clin Invest.

Slusarczyk, P., and Mleczko-Sanecka, K. (2021). The Multiple Facets of Iron Recycling. Genes (Basel) 12.

Sorbie, J., and Valberg, L.S. (1974). Iron balance in the mouse. Lab Anim Sci 24, 900-904.

Sukumaran, A., Chang, J., Han, M., Mintri, S., Khaw, B.A., and Kim, J. (2017). Iron overload exacerbates age-associated cardiac hypertrophy in a mouse model of hemochromatosis. Sci Rep 7, 5756.

Suliman, H.B., Keenan, J.E., and Piantadosi, C.A. (2017). Mitochondrial quality-control dysregulation in conditional HO-1(-/-) mice. JCI Insight 2, e89676.

Theurl, I., Hilgendorf, I., Nairz, M., Tymoszuk, P., Haschka, D., Asshoff, M., He, S., Gerhardt, L.M., Holderried, T.A., Seifert, M., et al. (2016). On-demand erythrocyte disposal and iron recycling requires transient macrophages in the liver. Nat Med 22, 945-951.

Torrance, J.D., and Bothwell, T.H. (1968). A simple technique for measuring storage iron concentrations in formalinised liver samples. The South African journal of medical sciences 33, 9-11.

Vijayan, V., Wagener, F., and Immenschuh, S. (2018). The macrophage heme-heme oxygenase-1 system and its role in inflammation. Biochem Pharmacol 153, 159-167.

$\mathrm{Xu}$, J., Knutson, M.D., Carter, C.S., and Leeuwenburgh, C. (2008). Iron accumulation with age, oxidative stress and functional decline. PLoS One 3, e2865.

Yona, S., Kim, K.W., Wolf, Y., Mildner, A., Varol, D., Breker, M., Strauss-Ayali, D., Viukov, S., Guilliams, M., Misharin, A., et al. (2013). Fate mapping reveals origins and dynamics of monocytes and tissue macrophages under homeostasis. Immunity 38, 79-91. 
Youssef, L.A., Rebbaa, A., Pampou, S., Weisberg, S.P., Stockwell, B.R., Hod, E.A., and Spitalnik, S.L. (2018). Increased erythrophagocytosis induces ferroptosis in red pulp macrophages in a mouse model of transfusion. Blood 131, 2581-2593.

Zhang, D.L., Wu, J., Shah, B.N., Greutelaers, K.C., Ghosh, M.C., Ollivierre, H., Su, X.Z., Thuma, P.E., Bedu-Addo, G., Mockenhaupt, F.P., et al. (2018). Erythrocytic ferroportin reduces intracellular iron accumulation, hemolysis, and malaria risk. Science 359, 1520-1523.

Zhang, Z., Zhang, F., An, P., Guo, X., Shen, Y., Tao, Y., Wu, Q., Zhang, Y., Yu, Y., Ning, B., et al. (2011). Ferroportin1 deficiency in mouse macrophages impairs iron homeostasis and inflammatory responses. Blood 118, 1912-1922. 